\title{
Matching the phenology of Net Ecosystem Exchange and Vegetation Indices estimated with MODIS and FLUXNET in- situ observations
}

\author{
M. Balzarolo', S. Vicca ${ }^{1}$, A. L. Nguy-Robertson ${ }^{2}$, D. Bonal ${ }^{3}$, J. A. Elbers ${ }^{4}$, Y. H. Fu' ${ }^{1,5}$, \\ T. Grünwald ${ }^{6}$, J. A. Horemans ${ }^{1}$, D. Papale ${ }^{7}$, J. Peñuelas ${ }^{8,9}$, A. Suyker ${ }^{2}$, F. \\ Veroustraete $^{10}$
}

[1] Center of Excellence PLECO (Plant and Vegetation Ecology), Biology Department, University of Antwerp, Universiteitsplein 1, B-2610 Wilrijk, Belgium

[2] School of Natural Resources, University of Nebraska-Lincoln, Nebraska, U.S.A.

[3] INRA, UMR EEF, 54280 Champenoux, France

[4] Alterra, Wageningen UR, Droevendaalsesteeg 3, 6708PB, Wageningen, The Netherlands

[5] College of Urban and Environmental Sciences, Peking University, Yiheyuan Road 5, 100871 Beijing, China

[6] Technische Universität (TU) Dresden, Institute of Hydrology and Meteorology, Chair of Meteorology, D-01062 Dresden, Germany

[7] Department for Innovation in Biological, Agro-food and Forest systems (DIBAF), University of Tuscia, Via S.C. de Lellis snc, 01100 Viterbo, Italy 
[8] CSIC, Global Ecology Unit CREAF-CSIC-UAB, 08913 Cerdanyola del Vallès, Catalonia, Spain.

[9] CREAF, 08913 Cerdanyola del Vallès, Catalonia, Spain.

[10] University of Antwerp, Faculty of Sciences, Department of Bioscience Engineering, Groenenborgerlaan 171, B-2020 Antwerpen, Belgium

Correspondence to: M. Balzarolo (manuela.balzarolo@uantwerpen.be)

Keywords: Vegetation Indices (VI's), Net Ecosystem Exchange (NEE), Start of Net Carbon Uptake (SGS NEE ), Start of Growing Season (SGS), Plant Functional Types (PFT's), Phenology.

\section{Abstract}

Shifts in ecosystem phenology play an important role in the definition of inter-annual variability of net ecosystem carbon uptake. A good estimate at the global scale of ecosystem phenology, 
mainly that of photosynthesis or gross primary productivity (GPP), may be provided by vegetation indices derived from MODIS satellite image data.

However, the relationship between the start date of a growing (or greening) season (SGS) when derived from different vegetation indices (VI's), and the starting day of carbon uptake is not well elucidated. Additionally, the validation of existing phenology data with in-situ measurements is largely missing. We have investigated the possibility to use different VI's to predict the starting day of the growing season for 28 FLUXNET sites as well as MODIS data. This analysis included main plant functional types (PFT's).

Of all VI's taken into account in this paper, the NDVI (Normalised Difference Vegetation Index) shows the highest correlation coefficient for the relationship between the starting day of the growing season as observed with MODIS and in-situ observations. However, MODIS observations elicit a 20-21 days earlier SGS date compared to in-situ observations. The prediction for the NEE start of the growing season diverges when using different VI's, and seems to depend on the amplitude for carbon and VI and on PFT. The optimal VI for estimation of a SGS date was PFT-specific - for example the WRDVI for cropland, but the MODIS NDVI performed best when applied as an estimator for Net Ecosystem Exchange and when considering all PFT's pooled.

\section{Introduction}

Ecosystem phenology shifts play an important role in describing the inter-annual variability of NEE (Net Ecosystem Exchange) due to its impact on Gross Primary Productivity (GPP). A shift in the start date of a growing season modulates annual GPP (Churkina et al. 2005; Keenan et al. 
2014; Richardson et al. 2010). Multiple data sources - primarily carbon dioxide $\left(\mathrm{CO}_{2}\right)$ eddy covariance flux data (NEE) as well as satellite imagery estimated vegetation indices (VI's) originating from different databases are used to estimate the start day of a growing season (Garrity et al. 2011).

GPP and NEE seasonality is frequently defined as carbon-flux phenology. Both variables describe the seasonality of ecosystem gross photosynthesis. Photosynthetic phenology is represented by the starting day of GPP and NEE and more specifically when NEE becomes positive. Explicitly the date when this occurs is by definition the day $\left(\mathrm{SGS}_{\mathrm{NEE}}\right)$ when an ecosystem transforms from a carbon source into a carbon sink. SGS NEE $_{\text {can }}$ be estimated in different ways. Eddy covariance data is on track to make the estimate (Baldocchi et al. 2005). On the other hand, leaf phenology can also be observed and defined with remote sensing based methods (Garrity et al., 2011). The exercise is to estimate the starting day of greening (SGS MODIS and SGS $_{\text {in-situ }}$ ) using an optical sensor (MODIS or in-situ). Intuitively, this is expected to correspond to $\mathrm{SGS}_{\mathrm{NEE}}$, but this relationship, and hence the predictability of $\mathrm{SGS}_{\mathrm{NEE}}$ from optical sensors, has yet to be verified. It is assumed in this paper that a correspondence with $\mathrm{SGS}_{\mathrm{NEE}}$ exists. It is the objective of this paper to verify, even validate this correspondence and hence whether SGS $S_{\text {NEE }}$ can be estimated from a space remote sensing platform (TERRA MODIS).

Several studies highlight a new application of remote sensing e.i., the integration of remote sensing data as well as NEE and GPP data collected with the eddy covariance method, to predict and map terrestrial carbon assimilation at the global and regional scales (Heinsch et al. 2006; Verma et al. 2014). An important step in this research venture is to establish a correspondence between phenological data - observed with remote sensing - versus in-situ optical and eddy covariance flux data. 
Remote sensing facilitates the global observation of the starting day of a growing season defined as the starting day of gross photosynthesis. Several approaches are applied to monitor changes in canopy development. These include changes in greening, acquired by digital camera imagery (Betancourt et al. 2005; Richardson et al. 2009), spectral spaces, reflectance and reflectance relationships (Nguy-Robertson et al. 2012) and vegetation indices (Wu 2014; Zhang et al. 2003). The latter is a common approach and has been applied using proximal sensors, such as radiometers (Huemmrich et al. 1999) or modified cameras (Petach et al. 2014; Sakamoto et al. 2010), and satellite sensor imagery (Walker et al. 2014).

Several VI's are considered as a useful estimator of bio-geophysical and biochemical parameters regulating leaf and canopy phenology and hence, productivity. Typical bio-geophysical variables derived from remote sensing platforms are leaf area index (LAI) and chlorophyll a and b (Gitelson et al. 2006; Myneni et al. 2002). A great variety of VI's have been defined by remote sensing scientists and all differ in their definition and in their sensitivity to changes in photosynthesis as well. These so-called "Greenness indices" - such as the widely used Normalized Difference Vegetation Index (NDVI) (Tucker 1979) - demonstrate to be a good proxy for the fraction of absorbed PAR (fAPAR) and PAR is Photosynthetically Active Radiation and APAR is absorbed PAR. By definition, $f$ APAR $=$ APAR/PAR. Hence $f$ APAR and the NDVI are related with green biomass and canopy structure. Furthermore, the NDVI has been recognised to be a good proxy for the investigation of the impact of climate change on leaf and ecosystem phenology (Peng et al. 2013; Piao et al. 2015).

In addition to the NDVI, many other vegetation indices have also been defined. Among many others one can cite: the Enhanced Vegetation Index (EVI) (Huete et al. 1997). Both the NDVI and EVI allow the observation of canopy greening based on their dependency on the RED and 
near infrared (NIR) parts of the electromagnetic spectrum (Huete et al. 2002; Piao et al. 2006; Reed et al. 1994). The EVI is generally less sensitive to soil background variations compared to other VI's when vegetation cover fraction (fCover) is low (Huete et al. 2002). The EVI incorporates an additional blue spectral band in addition to the commonly used RED and NIR spectral bands. The use of a blue band is intended to reduce atmospheric scattering effects typically due to the interaction of - most strongly, blue - light with aerosols and atmospheric molecules. The EVI definition reduces noise, but its applicability is limited to those sensors which dispose of a blue band, which puts a limit on the number of satellite sensors which can be used for global studies.

Jiang et al. (2008) proposed an alternative definition for the EVI, e.g., the EVI2 in which the blue spectral band is substituted by a red band. Though EVI2 does not make use of a blue band, EVI2 has been determined to be equivalent to EVI and seems helpful to observe canopy properties. A benefit of EVI and EVI2 is that they remain more sensitive than the NDVI when canopies become denser. However, even these vegetation indices do saturate at moderate LAI values (Viña et al. 2011). Alternatively, the Wide Dynamic Range Vegetation Index (WDRVI) seems more sensitive for the entire dynamic range of the LAI (Gitelson 2004). The Simple Ratio (SR) however has been shown to be the most sensitive VI at high LAI values (Viña et al. 2011).

The Global Environmental Monitoring Index (GEMI) has been defined based on RED and NIR band reflectances. GEMI minimizes atmospheric effects, similar to the EVI and minimizes observational angular effects as well (e.g. BRDF effects) in the observed VI signal (Pinty and Verstraete, 1992). Nevertheless GEMI is rarely used in canopy phenology observations.

The Soil Adjusted Vegetation index (SAVI) has been defined to minimize the influence of soil brightness (Huete 1988). The SAVI involves the RED and NIR reflectance bands and a soil 
brightness correction factor (L). L equals zero for a very high vegetation cover and unity for nonvegetated land surfaces. Typically, $\mathrm{L}$ is assumed to be 0.5 for most vegetated areas. By definition SAVI equals the NDVI when L equals zero.

A variety of in-situ optical sensors are commercially available for field, UAV and airborne applications. They acquire NIR and RED band reflectances at top-of-the-canopy level (Balzarolo et al. 2011). PAR sensors can be applied as broadband sensors for reflectances in the visible spectral range. These data can then be used instead of RED band imagery, to calculate vegetation indices. Likewise, pyranometers are sensitive in the global shortwave radiation band (GLR) and they can be applied as a NIR sensitive reflectance band. GLR spans a broad spectral range, including the visible, NIR, and mid-infrared spectral regions. The visible spectral region in the GLR band can be brought to zero reflectance using the PAR sensor signal (Jenkins et al. 2007; Wang et al. 2004). With this approach in-situ NDVI can be derived from measurements of the PAR band (400-700 $\mathrm{nm})$; and a visible corrected GLR band (700-2800 $\mathrm{nm})$.

In-situ NDVI measurements provide distinct advantages. They are typically endowed with a high temporal resolution since they acquire data at an hourly basis and can be programmed for data collection at even higher frequencies. Important to mention is that in-situ NDVI measurements offer the possibility for data acquisition under overcast conditions. Only low altitude remote sensing systems like UAV's offer this capacity as well.

Finally, the objective of this paper is to explore the potential of six different VI's calculated from in-situ radiation measurements, and obtained from MODIS RED and NIR reflectances. This enables the estimation of the start of the carbon uptake season (i.e. SGS $S_{\mathrm{NEE}}$ ). Additionally the approach should also enable the phenological monitoring at twenty-eight different FLUXNET sites encompassing eight different PFT's (or ecosystems). 
The specific objectives pursued in this paper are:

(i) How well do SGS estimations derived from in-situ vegetation indices (referred to as SGS $_{\text {in-situ }}$ ) correlate with SGS estimations derived from MODIS VI's (referred to as SGS $_{\text {MODIS }}$ ) and secondly;

(ii) Which VI's as well as sensors are optimal for SGS $\mathrm{SEE}_{\mathrm{N}}$ detection based on in-situ NEE flux data collected at FLUXNET sites.

\section{$2 \quad$ Materials and methods}

\subsection{FLUXNET data: site selection}

The study presented in this paper is based on VI's, determined with remote sensing and carbon flux measurements acquired from the FLUXNET eddy covariance network (www.fluxdata.org, "La Thuile" database, October 2010). The FLUXNET database contains half-hourly observations of ecosystem $\mathrm{CO}_{2}$, heat fluxes and meteorological data of more than 250 sites worldwide and for a total of 960 site-years. The most representative sites used in this study have been selected based on the following boundary conditions:

(i) The availability of continuous measurements of global incoming and outgoing shortwave radiation $\left(\mathrm{GLR}_{\mathrm{in}}\right.$ and $\left.\mathrm{GLR}_{\text {out }}\right)$ respectively, since both are required to calculate in-situ VI's;

(ii) The availability of continuous measurements of global incoming and outgoing PAR (PAR in $_{\text {PAR }}$ out), since both are required to calculate in-situ VI's;

(iii) The availability of measured carbon mass fluxes (in particular NEE). 
The application of these boundary conditions, leads to a subset of 28 FLUXNET sites (Table 1), representing 72 site-years. They have a minimum of two years of both high quality flux measurements and measured radiation data. The 28 sites have been selected to establish the basic dataset used for the different procedures and analysis of which the results and conclusions are reported in this paper.

The selected sites cover main global PFT's among which: CRO_Cropland; DBF-Deciduous Broadleaf Forest; EBF_Evergreen Broadleaf Forest; ENF_Evergreen Needle-leaf Forest; GRA — Grassland; OSH_-Open Shrubland; WSA — Woody Savanna.The PFT's are defined as in the International Geosphere-Biosphere Programme - IGBP (Loveland and Belward 1997).

\section{[Table 1]}

Table 1 - Description of FLUXNET sites, years of measurement and PFTs used in this study (CRO_Cropland; DBF_-Deciduous Broadleaf Forest; EBF-Evergreen Broadleaf Forest; ENF-Evergreen Needle-leaf Forest; GRA_-Grassland; OSH-Open Shrubland; WSAWoody Savanna).

\begin{tabular}{llccccc} 
Site ID & Site name & Country & $\begin{array}{r}\text { Lat } \\
\text { [decimal } \\
\text { degrees }]\end{array}$ & $\begin{array}{r}\text { Lon } \\
{[\text { decimal }} \\
\text { degrees }]\end{array}$ & $\begin{array}{c}\text { Plant } \\
\text { Functional } \\
\text { Type }\end{array}$ & $\begin{array}{c}\text { Measurement } \\
\text { Interval } \\
\text { (Years) }\end{array}$ \\
\hline BR-Cax & Caxiuana Forest-Almeirim & Brazil & -1.719720 & -51.459000 & EBF & $1999-2002$ \\
BR-Sa2 & Santarem-Km77-Pasture & Brazil & -3.011900 & -54.536499 & CRO & $2001-2002$ \\
BR-Sa3 & Santarem-Km83-Logged Forest & Brazil & -3.018030 & -54.971401 & EBF & $2002-2003$
\end{tabular}




\begin{tabular}{|c|c|c|c|c|c|c|}
\hline BR-Sp1 & Sao Paulo Cerrado & Brazil & -21.619499 & -47.649899 & WSA & 2001-2002 \\
\hline CA-NS5 & UCI-1981 burn site & Canada & 55.863098 & -98.485001 & ENF & 2004-2005 \\
\hline CA-NS6 & UCI-1989 burn site & Canada & 55.916698 & -98.964401 & $\mathrm{OSH}$ & 2002-2005 \\
\hline CA-NS7 & UCI-1998 burn site & Canada & 56.635799 & -99.948303 & $\mathrm{OSH}$ & 2003-2005 \\
\hline DE-Geb & Gebesee & Germany & 51.100101 & 10.914300 & $\mathrm{CRO}$ & 2004-2006 \\
\hline DE-Hai & Hainich & Germany & 51.079300 & 10.452000 & DBF & 2004-2006 \\
\hline DE-Kli & Klingenberg - cropland & Germany & 50.892899 & 13.522500 & CRO & 2004-2006 \\
\hline DE-Meh & Mehrstedt 1 & Germany & 51.275299 & 10.655500 & GRA & 2004-2006 \\
\hline DE-Tha & Anchor Station Tharandt - old spruce & Germany & 50.963600 & 13.566900 & ENF & 2005-2006 \\
\hline DE-Wet & Wetzstein & Germany & 50.453499 & 11.457500 & ENF & 2004-2006 \\
\hline FI-Hyy & Hyytiala & Finland & 61.847401 & 24.294800 & ENF & 2004-2006 \\
\hline GF-Guy & Guyaflux & French Guiana & 5.277700 & -52.928799 & $\mathrm{EBF}$ & 2004-2006 \\
\hline JP-Tak & Takayama & Japan & 36.146198 & 137.423004 & DBF & 1999-2004 \\
\hline JP-Tom & Tomakomai National Forest & Japan & 42.739498 & 141.514893 & DBF & 2001-2003 \\
\hline NL-Loo & Loobos & Netherlands & 52.167900 & 5.743960 & ENF & 2005-2006 \\
\hline $\begin{array}{l}\text { US- } \\
\text { ARM }\end{array}$ & $\begin{array}{l}\text { ARM Southern Great Plains site- } \\
\text { Lamont }\end{array}$ & USA & 36.605801 & -97.488800 & $\mathrm{CRO}$ & 2005-2006 \\
\hline US-Bar & Bartlett Experimental Forest & USA & 44.064602 & -71.288078 & DBF & 2004-2005 \\
\hline US-Bo1 & Bondville & USA & 40.006199 & -88.290398 & $\mathrm{CRO}$ & 2003-2006 \\
\hline US-CaV & Canaan Valley & USA & 39.063301 & -79.420799 & GRA & 2004-2005 \\
\hline US-FPe & Fort Peck & USA & 48.307701 & -105.101898 & GRA & 2004-2006 \\
\hline US-Goo & Goodwin Creek & USA & 34.254700 & -89.873497 & GRA & 2002-2006 \\
\hline US-MOz & Missouri Ozark Site & USA & 38.744099 & -92.199997 & DBF & 2005-2006 \\
\hline US-Ne2 & $\begin{array}{l}\text { Mead - irrigated maize-soybean } \\
\text { rotation site }\end{array}$ & USA & 41.164902 & -96.470100 & $\mathrm{CRO}$ & 2001-2004 \\
\hline US-Ne3 & $\begin{array}{l}\text { Mead - rainfed maize-soybean rotation } \\
\text { site }\end{array}$ & USA & 41.179699 & -96.439697 & $\mathrm{CRO}$ & 2002-2004 \\
\hline US-SRM & Santa Rita Mesquite & USA & 31.821400 & -110.865997 & WSA & 2004-2006 \\
\hline
\end{tabular}

Furthermore, nine additional sites have been selected from the FLUXNET "La Thuile" database, representing 20 site-years, (cited in Table S1 in the Supplementary data; validation sites). They were used as an independent evaluation (validation) of NEE phenology compared with the more common descriptors of phenology (i.e. fAPAR and EVI). These validation sites have been selected because they have acquisitions of all radiation components required to derive fAPAR: incident PAR at the top of the canopy (i.e. $\left.\mathrm{PAR}_{\text {in }}\right)$ and below canopy PAR (PAR $\left.\mathrm{P}_{\mathrm{bc}}\right)$. 
More details on NEE phenology evolution are given in section 2.4.1. Two of the FLUXNET validation sites (i.e. DE-Tha and FI-Hyy) have also been used as well, in the main analysis.

\subsubsection{In-situ radiation measurements}

The most commonly used instrument for the measurement of $\mathrm{PAR}_{\text {in }}$ and $\mathrm{PAR}_{\text {out }}$ at the flux tower sites, is the quantum sensor. In a typical set-up at a FLUXNET site, an upward facing quantum sensor is used to measure $\mathrm{PAR}_{\text {in }}$ while concomitantly a downward facing sensor measures

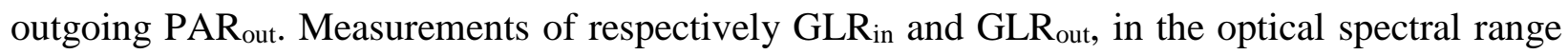
(305 to $2800 \mathrm{~nm}$ ) have been performed with two pyranometers, of which one faces upward to measure $\mathrm{GLR}_{\text {in }}$, and the other faces downward to measure GLR $_{\text {out. More details on radiation }}$ sensor set-ups at the FLUXNET sites are given by Balzarolo et al. (2011).

\subsubsection{Carbon flux measurements}

Eddy covariance (EC) measurements of ecosystem $\mathrm{CO}_{2}$ mass fluxes have been acquired from the FLUXNET database (Baldocchi et al. 2001). EC data are collected by the site manager according to a standard procedure and provide to the FLUXNET database. Typically data are collected at high sampling frequencies (at least at $10 \mathrm{~Hz}$ ) and subsequently converted into mass fluxes integrated over a thirty minute time interval. Here, we used gap-filled NEE data from FLUXENT "La Thuile" database (www.fluxdata.org, October 2010) where half hourly data are processed following the standardized methodology described in Papale et al. (2006) and Reichstein et al. (2005). In particular, the NEE data are storage corrected, spike filtered, $\mathrm{u}^{*}$-filtered, and subsequently gap-filled. The datasets thus obtained typically correspond with a source area footprint of hundreds of meters in the vicinity of the EC tower, depending on tower and vegetation height (Schmid 2002). 


\subsection{Computation of in-situ Vl's from in-situ radiation measurements}

In-situ VI's are calculated from half-hourly in-situ acquisitions of $\mathrm{PAR}_{\text {in }}, \mathrm{PAR}_{\text {out }}, \mathrm{GLR}_{\text {in }}$ and GLR $_{\text {out }}$ according to the method proposed by Huemmrich et al. (1999). PAR reflectance ( $\rho_{\mathrm{PAR}}$, $400-700 \mathrm{~nm})$ is derived from PAR $_{\text {in }}$ and PAR out $_{\text {out }}$ measurements. NIR Reflectance $(700-2800 \mathrm{~nm})$ is derived from GLR in and PAR in and GLR out and PAR out measurements. Summarizing, $\rho_{\mathrm{PAR}}$ and $\rho_{\mathrm{NIR}}$ are calculated according to Eq. 1 and 2:

$$
\begin{aligned}
& \rho_{P A R}=\frac{P A R_{\text {out }}}{P A R_{\text {in }}} \\
& \rho_{\mathrm{N} I R}=\frac{G L R_{\text {out }}-P A R_{\text {out }}}{G L R_{\text {in }}-P A R_{\text {in }}}
\end{aligned}
$$

The physical units of both incoming and outgoing PAR are obtained by a physical unit conversion $\mu$ mol.photons. $\mathrm{m}^{-2} \cdot \mathrm{s}^{-1}$ to $\mathrm{J} \mathrm{m}^{-2} \mathrm{~s}^{-1}$ using a conversion factor of $4.55 \mu \mathrm{mol} . \mathrm{J}^{-1}$ as proposed by Goudriaan and Van Laar (1994).

In-situ data are calculated as an average of five observations per hour before and after solar noon (i.e. between $11 \mathrm{~h} 00$ and $13 \mathrm{~h} 00$ local solar time (LST)) for each of the 28 main sites. In-situ VI's (Table 2) are derived using $\rho_{\text {PAR }}$ and $\rho_{\text {NIR }}$ reflectances and calculated according to eq. 1 and eq. 2. The acquisition dates of MODIS 8-day composite NDVI data are used to obtain representative in-situ VI data.

\section{[Table 2]}


Table 2 - Definitions of MODIS and in-situ VIs. See running text for a definition of $\rho_{\text {NIR }}$ and $\rho_{\text {PAR }}$.

\begin{tabular}{|c|c|c|}
\hline VI & Definition & Literature reference \\
\hline $\begin{array}{l}\text { Normalized Difference Vegetation } \\
\text { Index (NDVI) }\end{array}$ & $N D V I=\frac{\rho_{\mathrm{NIR}}-\rho_{P A R}}{\rho_{\mathrm{N} I R}+\rho_{P A R}}$ & Rouse et al., 1974 \\
\hline Simple Ratio (SR) & $S R=\frac{\rho_{\mathrm{NIR}}}{\rho_{P A R}}$ & Rouse et al., 1974 \\
\hline $\begin{array}{l}\text { Wide Range Dynamic Vegetation } \\
\text { Index (WRDVI) }\end{array}$ & $\begin{array}{l}W R D V I=\frac{a \rho_{\mathrm{NIR}}-\rho_{P A R}}{a \rho_{\mathrm{N} I R}+\rho_{P A R}} \\
a=0.1\end{array}$ & Gitelson et al., 2004 \\
\hline Enhanced Vegetation Index 2 (EVI2) & $E V I 2=\frac{2.5 *\left(\rho_{\mathrm{N} I R}-\rho_{P A R}\right)}{\rho_{\mathrm{N} I R}+2.4 * \rho_{P A R}+1}$ & Jiang et al., 2008 \\
\hline Global Environmental Monitoring & $G E M I=\eta(1-0.25 \eta)-\frac{\rho_{P A R}-0.125}{1-\rho_{P A R}}$ & Pinty and Verstraete, \\
\hline Index (GEMI) & $\eta=\frac{2\left(\rho_{N I R}^{2}-\rho_{P A R}^{2}\right)+1.5 \rho_{N I R}+0.5 \rho_{P A R}}{\rho_{N I R}+\rho_{P A R}+0.5}$ & 1992 \\
\hline $\begin{array}{l}\text { Soil-Adjusted vegetation index } \\
\text { (SAVI) }\end{array}$ & $\begin{array}{l}S A V I=\frac{\rho_{\mathrm{NIR}}-\rho_{P A R}}{\rho_{\mathrm{N} I R}+\rho_{P A R}+L} *(1+L) \\
L=0.5\end{array}$ & Huete, 1988 \\
\hline & $\mathrm{L}$ is the soil brightness correction factor & \\
\hline
\end{tabular}

The quality assessment and control (QA/QC) of half-hourly radiometric measurements is performed applying various physical limit tests. Typically, GLR $\mathrm{in}_{\mathrm{n}}$ has to be less than the corresponding extraterrestrial radiation $\left(R_{\text {ext }}\right)$ at the same point in time (hence $\left.G L R_{\text {in }}<R_{\text {ext }}\right)$. An analysis of the statistical variability of the data (quantified by the standard deviation, $\sigma$ ) has been performed as well in the QA/QC procedure. As a matter of fact $\mathrm{GLR}_{\text {in }}$ can only be larger than 
$\mathrm{R}_{\mathrm{ext}}$ for high latitude regions (hence, above the $65^{\circ}$ Northern or $65^{\circ}$ Southern latitudes) and only under the condition that convective clouds are present (Yang et al. 2010). Physically, at the Earth's surface, GLR in when interacting with clouds and aerosols always drops to values lower than $\mathrm{R}_{\mathrm{ext}}$ for all optical wavelengths. Henceforth, the Atmospheric Impact Ratio (AIR) or AIR = $\mathrm{GLR}_{\text {in }} / \mathrm{R}_{\text {ext }}$ must always be smaller or equal to unity, the last case only under exo-atmospheric conditions.

The variation of AIR $\left(\sigma_{\text {AIR }}\right)$ between two successive 30 minutes measurement intervals cannot exceed 0.75 . A smaller $\sigma_{\text {AIR }}$ value indicates a pyranometer failure. For example $\sigma_{\text {AIR }}$ will be equal to zero when a pyranometer ceases to operate for a considerable period. Conversely, when a pyranometer works intermittently, the variability of $\sigma_{\text {AIR }}$ becomes unrealistically high. Hence, half-hourly radiometric acquisitions are flagged out for further use, when the following boundary condition is met:

$$
\frac{1}{8} \mu\left(\frac{G L R_{\text {in }}}{R_{\text {ext }}}\right)<\sigma\left(\frac{G L R_{\text {in }}}{R_{\text {ext }}}\right) \leq 0.35 .
$$

This QA/QC statistic is computed using half-hourly radiation measurements acquired between sunrise and sunset. In-situ VI's as defined in Table 2, are computed at half hour time intervals from the radiometric data when these are not rejected by the QA/QC procedure criteria as described above.

\subsection{MODIS products}

We used the 8-day $500 \mathrm{~m}$ surface reflectance product (MOD09G1, collection 5) from the MODIS/TERRA satellite sensor/platform as provided by ORNL DAAC (see http://daac.ornl.gov/cgi-bin/MODIS/GR_col5_1/mod_viz.html). MOD09G1 pixels matching the coordinates of a FLUXNET site have been extracted. The VIs, as reported in Table 2, are 
calculated from these surface reflectance values using band 1 (red: 620-670 nm) and band 2 (NIR: 841-876 nm). 8-day MOD09G1 pixel values represent the optimal reflectance values for 8-day compositing windows, selecting pixels with optimal viewing angles and minimal cloud or cloud shadow impacts. Extracted time series Quality Assurance / Quality Control (QA/QC) flags have been used, ensuring the quality of the MOD09G1 product. Specifically the MOD35 QA/QC flags have been used to identify the presence of snow (i.e. "MOD35 snow/ice" flags equal to “no"), clouds and cloud shadows (i.e. "MOD35 cloud" flags equal to "clear"). The MOD09G1

reflectance bands at $500 \mathrm{~m}$ were flagged as having the optimal quality for all bands (i.e. “MODLAND QA bits" flags equal to "corrected product produced at ideal quality all bands"). Only the pixels with the highest quality (e.g. clear conditions without snow) have been selected and retained for further use.

\subsection{Canopy phenological variable derivation from NEE and in-situ and MODIS VI's}

Canopy phenological variables are derived using MODIS as well as in-situ VI's as well as NEE time-series data. TIMESAT v.3.1 software has been selected for VI time-series processing. TIMESAT is available at the following URL: http:/www.nateko.lu.se/TIMESAT/timesat.asp (Jonsson and Eklundh 2002; 2004).

With respect to TIMESAT options for use, the adaptive Savitzky-Golay method for time-series smoothing and the double sigmoid method to extract seasonally dependent variables from a timeseries have been selected for application. By definition, the adaptive Savitzky-Golay method smooths a time-series with a total of $\mathrm{N}$ points $i$, which comply with: $\left(t_{i}, V_{i}\right)$ with taking values of $i$ $=1,2, \ldots, N$. Each point $i$ is fitted with a quadratic polynomial function as defined by eq. 3 : 


$$
f(\mathrm{t})=c_{1}+c_{2} \mathrm{t}+c_{3} \mathrm{t}^{2}
$$

For all $2 k+1$ points within a time window ranging from $n=i-k$ to $m=i+k$, a linear combination of nearby values is solved according to eq. 4 :

$$
\sum_{\mathrm{j}}^{\mathrm{n}}=\mathrm{c}_{\mathrm{j}} \mathrm{V}_{\mathrm{i}+\mathrm{j}}
$$

In the simplest case, coefficients $c_{j}$ are defined as $c_{j}=1 /(2 n+1)$ while the data value $V_{i}$ is replaced by the average of the data values in the time window as defined earlier. Time window extent determines the amplitude of the degree of VI time-series smoothing.

A fitting time window of $\mathrm{N}=4$ points $\mathrm{i}$ has been used to represent the temporal variability of NEE fluxes as well as both VI types, i.e. the MODIS and in-situ VI's. A double sigmoid is applied to be fitted through each smoothed time-series of beforementioned data types:

$$
V(t)=\frac{1}{1+e^{\frac{v i_{1}-t}{v i_{2}}}}-\frac{1}{1+e^{\frac{v i_{3}-t}{v i_{4}}}}
$$

In eq. 5:

- $v i_{1}$ is the position of the $\mathrm{V}$ curve part before an inflection point;

- $v i_{2}$ is the rate of change of the variable curve before an inflection point;

- $v i_{3}$ is the position of the $\mathrm{V}$ curve part after an inflection point and;

- $v i_{4}$ is the rate of curve change after an inflection point.

The main phenological variables - the start and end of a growing season amplitude - are determined by a threshold method as implemented in TIMESAT. A seasonal starting point (i.e. SGS $_{\mathrm{NEE}}$ for NEE; SGS MODIS for the MODIS VI's and $\mathrm{SGS}_{\text {in-situ }}$ for in-situ VI's) is defined using the double sigmoid function (see eq. 5) to determine the time point (in days) corresponding with 
$50 \%$ of the $\mathrm{V}$ time-series amplitude height and defined as the distance between the time-series left side minimal and maximal levels. The end of the a growing season is defined similarly, starting however from the time-series right side minimum.

\subsubsection{Evaluation of NEE phenology}

For the nine sites listed in Table S1 in the Supplementary data, NEE fluxes are continuosly measured, and the resulting $\mathrm{SGS}_{\mathrm{NEE}}$ date estimates are evaluated against a remote sensing variable and index respectively, commonly used to estimate flux phenology, e.i.,fAPAR and EVI. $f$ APAR is derived from both components of radiation (i.e. $\mathrm{PAR}_{\mathrm{in}}$ and $\mathrm{PAR}_{\mathrm{bc}}$ ) by using the formula given by Monteith (1993) as:

$$
f A P A R=1-\frac{P A R_{b c}}{P A R_{\text {in }}} e^{1.35}
$$

where PAR $\mathrm{P}_{\mathrm{bc}}$ is below canopy PAR and PAR $\mathrm{P}_{\text {in }}$ is incident PAR. The exponent with value 1.35, accounts for the mean effect of the different absorptivities in the PAR and global solar radiation spectral bands. QA/QC of the half-hourly $\mathrm{PAR}_{\mathrm{in}}$ and $\mathrm{PAR}_{\mathrm{bc}}$ data is performed applying the same tests as used to checking the quality of all other radiation measurements used to calculated VI's (see section 2.2).

EVI has been derived from the 8-day $500 \mathrm{~m}$ surface reflectance MODIS product (MOD09G1, collection 5, being the same dataset used for the main analysis in this study) and is calculated according to eq. 7 :

$$
E V I=2.5 * \frac{\left(\rho_{N I R}-\rho_{P A R}\right)}{\left.1+\rho_{N I R}+6 * \rho_{P A R}-7.5 * \rho_{\text {blue }}\right)}
$$


where $\rho_{\text {PAR }}$ is band $1(620-670 \mathrm{~nm}), \rho_{\text {NIR }}$ is band $2(841-876 \mathrm{~nm})$ and $\rho_{\text {blue }}$ is band $3(459-479$ $\mathrm{nm}$ ). Furthermore, the same QA/QC flags applied for the VI's calculated for MODIS (see section 2.3) have been used to check the QA/QC of the EVI time-series.

\subsection{Statistical analysis}

A correlation analysis is performed to investigate the relationship between $\mathrm{SGS}_{\mathrm{MODIS}}$ and $\mathrm{SGS}_{\text {in- }}$ situ. The relationship was characterised using the following statistics:

- the coefficient of determination $\left(\mathrm{R}^{2}\right)$;

- the root mean square error (RMSE) and;

- the normalized mean bias (NMB).

Differences between PFT's have been assessed for each VI applying a statistical analysis to quantify the correlation between $\mathrm{SGS}_{\text {MODIS }}$ and $\mathrm{SGS}_{\text {in-situ }}$ by binning FLUXNET sites according to PFT type. The robustness of the statistical analysis has been tested by a leave-one-out crossvalidation technique. The predictive performance is expressed as a cross-validated root mean square error $\left(\mathrm{RMSE}_{\mathrm{CV}}\right)$.

To test the impact of VI on the relation between $\mathrm{SGS}_{\text {MODIS }}$ and $\mathrm{SGS}_{\text {in-situ }}$, we performed a covariance analysis (ANCOVA) with $\mathrm{SGS}_{\mathrm{MODIS}}$ as response variable, $\mathrm{SGS}_{\text {in-situ }}$ as the explanatory variable of primary importance and VI as covariate using the PROC GLM routine implemented in SAS (SAS 9.4; OSAS Institute Inc., Cary, NC, USA). The relationship between

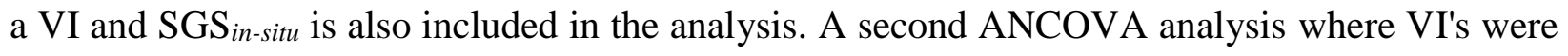
replaced by PFT's, has been performed to test the PFT impact on the SGS MODIS vs. SGS ${ }_{\text {in-situ }}$ relationship. 
A two by two comparison of the slope of the regression relationship between $\mathrm{SGS}_{\mathrm{MODIS}}$ and $\mathrm{SGS}_{\text {in-situ }}$ has been performed for the VI selected according to a best fit criterion (i.e. highest $\mathrm{R}^{2}$ and minimal RMSE value) compared to the other VI's investigated. A two by two comparison has been conducted to test the significance of differences in regression slopes between VI's eliciting the highest correlation between SGS $_{\text {MODIS }}$ and SGS $_{\text {in-situ }}$ compared to all other VI's.

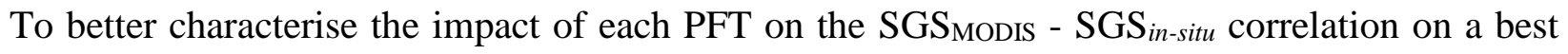
fit, a third ANCOVA analysis with as response variable SGSMODIS and explanatory variables $\mathrm{SGS}_{i n-s i t u}, \mathrm{PFT}$ and their interaction, has been performed.

The performance of SGS VI's intended to predict $\mathrm{SGS}_{\mathrm{NEE}}$, has been investigated similarly to the procedures described earlier in this chapter. However, the response variable selected for this case is $\mathrm{SGS}_{\mathrm{NEE}}$.

To confirm the hypothesis that differences between $\mathrm{SGS}_{\mathrm{NEE}}$ and respectively the SGS values derived from MODIS and in-situ VI's (i.e. SGS $\mathrm{SEE}_{-}$SGS $\mathrm{SODIS}_{\mathrm{M}}$ and $\mathrm{SGS}_{\mathrm{NEE}}-\mathrm{SGS}_{\text {in-situ}}$, respectively) are related to VI seasonality, VI type and PFT properties, we applied a general linear mixed effects model (GLMM). In this respect seasonality is represented by the amplitude of a VI time-series evaluated with the TIMESAT software. Using the GLMM, a boundary condition is that FLUXNET sites and measurement years are considered as random variables. Time as a variable (i.e. measurement year) is spatially nested (i.e. FLUXNET sites are spatially nested). The GLMM analysis is performed using the PROC MIXED routine implemented in SAS (SAS 9.4; CSAS Institute Inc., Cary, NC, USA). 


\section{Results}

\subsection{Comparison of SGS MODIS and SGS in-situ}

For all PFT's, MODIS VI's predict the date of the start of season earlier in time than for the insitu VI's (Table 3), SGS in-situ $_{\text {vs. }}$ SGS MODIs correlations differ according to VI type ( $\mathrm{F}=8.17$; $\mathrm{p}$ $<0.0001$, not shown in Table 3 nor Fig 1).

Clearly, the SGS estimated using the NDVI elicits the highest correlation coefficient for MODIS as well as in-situ observations (Fig. 1a; Table 3; $\mathrm{R}^{2}=0.68 ; \mathrm{p}<0.05$ ). For the NDVI, the

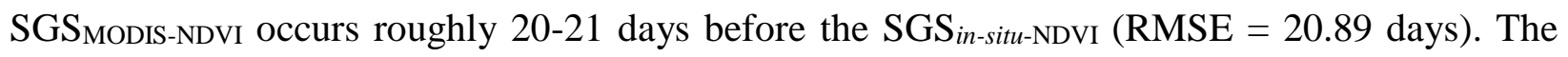
VI's, SR and WDRVI show quite satisfactory correlation coefficient values as well $\left(\mathrm{R}^{2}=0.43\right.$

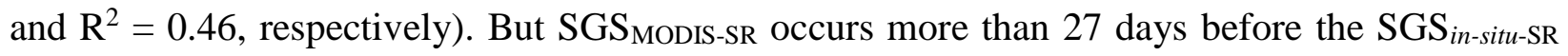
(see Table 3 - RMSE of SR). For all other VI's, the values of the correlation coefficients $\left(\mathrm{R}^{2}\right)$ drop below acceptable values for $\mathrm{SGS}_{\mathrm{MODIS}}$ and $\mathrm{SGS}_{\text {in-situ. }}$

A two by two comparison of the regression slopes of the VI relationships SGS $_{\text {MODIS }}$ vs. SGS ${ }_{\text {in-situ }}$ for the VI showing the highest $\mathrm{R}^{2}$ values (NDVI) versus each of the other VI's reveals that the SGS dates slopes derived from the SR and WDRVI VI's are not significantly different from the NDVI slope $(\mathrm{F}=1.47$ and $\mathrm{p}=0.14 ; \mathrm{F}=-0.99$ and $\mathrm{p}=0.32$, respectively, not shown in Table 3 nor Fig 1). 


\section{[Figure 1]}

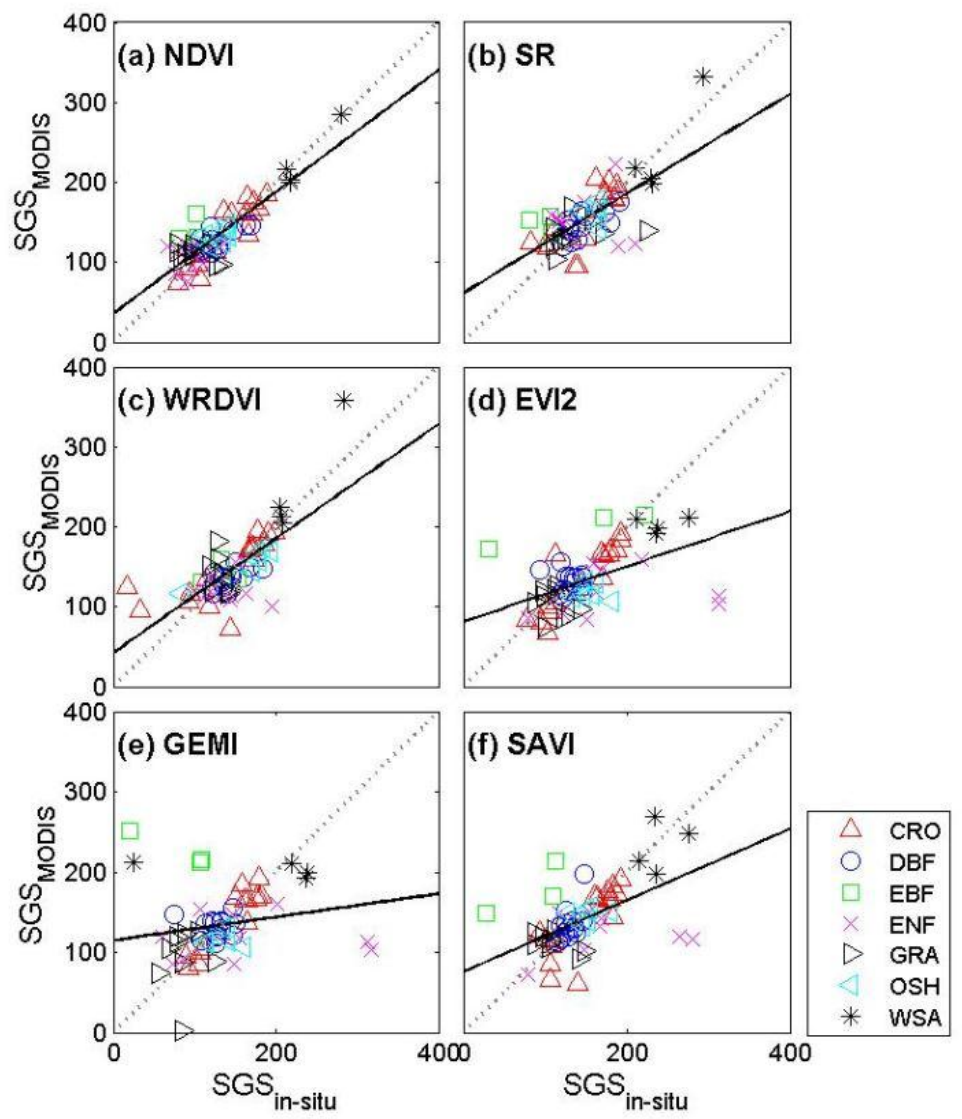

Figure 1 - Relationship between the start day of a growing season $\left(\mathrm{SGS}_{\text {in-situ }}\right)$ as derived from insitu and MODIS (SGS MODIS) VI's (see VI definitions in Table 2) for different PFT's (CROCropland; DBF_-Deciduous Broadleaf Forest; EBF-Evergreen Broadleaf Forest; ENFEvergreen Needle-leaf Forest; GRA-Grassland; OSH-Open Shrubland; WSA-Woody Savanna). Black lines represent linear interpolation functions (for all PFT's pooled), dotted lines 1:1 relationships. 


\section{[Table 3]}

Table 3 - Statistics of correlation analysis between the starting day of the growing season derived

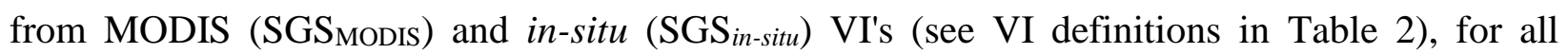
PFT's, pooled (see Fig. 1). N. obs—number of available sites and years; $\mathrm{R}^{2}$-coefficient of determination; RMSE—root mean square error; NMB—normalized mean bias; Y-int-yintercept of the linear model; Slope-slope of the linear model; $\mathrm{R}_{\mathrm{cv}}{ }^{2}-\mathrm{cross}$-validated coefficient of determination; and RMSE $\mathrm{cr}_{\mathrm{c}}$ cross-validated root mean square error. Bold letters indicate the model with the highest value of $\mathrm{R}^{2}$.

\begin{tabular}{|c|c|c|c|c|c|c|c|c|}
\hline & N. obs & $\begin{array}{l}\mathrm{R}^{2} \\
(-)\end{array}$ & $\begin{array}{c}\text { RMSE } \\
\text { (day) }\end{array}$ & $\begin{array}{l}\text { NMB } \\
\text { (day) }\end{array}$ & $\begin{array}{l}\text { Y-int } \\
\text { (day) }\end{array}$ & $\begin{array}{c}\text { Slope } \\
(-) \\
\end{array}$ & $\begin{array}{c}\mathrm{R}_{\mathrm{cv}}{ }^{2} \\
(-)\end{array}$ & $\begin{array}{c}\mathrm{RMSE}_{\mathrm{cv}} \\
\text { (day) }\end{array}$ \\
\hline \multicolumn{9}{|c|}{ SGS $_{\text {MOSIS vs. }}$ GGS $_{i n-s i t u}$} \\
\hline NDVI & 73 & $0.68^{*}$ & 20.89 & 0.0007 & 38.53 & 0.75 & 0.68 & 20.93 \\
\hline SR & 73 & $0.43^{*}$ & 27.22 & 0.0002 & 70.40 & 0.56 & 0.42 & 27.24 \\
\hline WRDVI & 71 & $0.46^{*}$ & 30.56 & 0.0000 & 55.62 & 0.63 & 0.46 & 30.48 \\
\hline EVI2 & 74 & $0.26^{*}$ & 32.73 & -0.0012 & 83.25 & 0.35 & 0.26 & 32.80 \\
\hline GEMI & 70 & 0.03 & 40.65 & 0.0004 & 117.29 & 0.13 & 0.03 & 40.67 \\
\hline SAVI & 71 & $0.24 *$ & 34.23 & -0.0002 & 84.80 & 0.39 & 0.25 & 34.26 \\
\hline
\end{tabular}

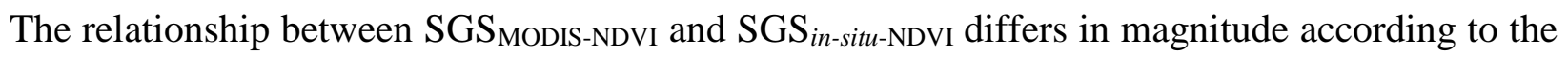
type of PFT (Table 4; F = 6.89; $\mathrm{p}<0.0001$ ). For SGS dates derived from the NDVI, woody savanna (SWA) elicits the highest correlation coefficient value (see Table 4). SGS MODISNDVI is only 11 days earlier than SGS $_{i n-\text { situ-NDVI. }}$ Cropland (CRO) SGS dates, derived with the NDVI, isof all PFT's considered, the one with the highest correlation coefficient $\left(\mathrm{R}^{2}=0.81\right)$. The RMSE 
value of 17.20 days is quite high though.. SGSMODIS-NDviand $\mathrm{SGS}_{\text {in-situ-NDVI }}$ dates are significantly correlated as well for deciduous forest (See Table 4: DBF, $\mathrm{R}^{2}=0.51$ and $\mathrm{RMSE}=$ 8.70). The SGS $\mathrm{SODIS}_{\text {-NDVI }}$ date occurs only 8 to 9 days before the $\mathrm{SGS}_{\text {in-situ-NDVI }}$ date. For the remaining PFT's, non-significant relationships were found (see Table 4).

\section{[Table 4]}

Table 4 - Statistics of the correlation between the start day of the growing season (SGS) derived

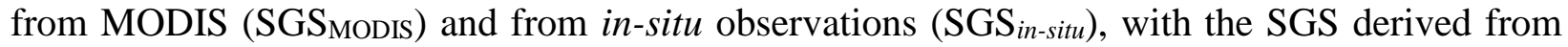
the NDVI for each PFT's considered in this paper. $\mathrm{R}^{2}$ — coefficient of correlation; RMSE—root mean square error; Y-int-y-intercept of the linear model; Slope-slope of the linear model; $\mathrm{R}_{\mathrm{cv}}{ }^{2}$ - cross-validated coefficient of determination; and $\mathrm{RMSE}_{\mathrm{cv}}$-cross-validated root mean square error. Bold letters indicate the model with the highest value of $\mathrm{R}^{2}$.

\begin{tabular}{lcccccccc}
\hline N.obs & $\begin{array}{c}\mathrm{R}^{2} \\
(-)\end{array}$ & $\begin{array}{c}\text { RMSE } \\
\text { (day) }\end{array}$ & $\begin{array}{c}\text { NMB } \\
\text { (day) }\end{array}$ & $\begin{array}{c}\text { Y-int } \\
\text { (day) }\end{array}$ & $\begin{array}{c}\text { Slope } \\
(-)\end{array}$ & $\begin{array}{c}\mathrm{R}_{\mathrm{cv}}^{2} \\
(-)\end{array}$ & $\begin{array}{c}\mathrm{RMSE}_{\mathrm{cv}} \\
(\text { day) }\end{array}$ \\
\hline SGS & & & & & & \\
\hline CRO & 19 & $0.81^{*}$ & 17.20 & 0.000 & 0.05 & 1.00 & 0.81 & 17.14 \\
DBF & 15 & $0.51^{*}$ & 8.70 & 0.001 & 73.76 & 0.42 & 0.50 & 8.88 \\
EBF & 5 & 0.68 & 24.50 & 0.073 & 105.20 & 0.49 & 0.76 & 24.08 \\
ENF & 10 & 0.04 & 16.84 & 0.012 & 89.18 & 0.17 & 0.05 & 17.28 \\
GRA & 13 & 0.14 & 13.97 & 0.007 & 141.22 & -0.28 & 0.15 & 14.35 \\
OSH & 7 & 0.35 & 9.95 & 0.003 & 66.12 & 0.51 & 0.30 & 9.86 \\
WSA & 4 & $\mathbf{0 . 9 4 *}$ & 11.93 & -0.007 & -48.12 & 1.18 & 0.96 & 11.11 \\
\hline \multicolumn{7}{c}{$*$ p-value $<0.05$} \\
\end{tabular}


A two by two comparison of the regression slope of the relationship SGS between woody savanna (WSA), the PFT with the best highest $\mathrm{R}^{2}$, and all other PFT's reveals that the correlation between WSA differs significantly from all other PFT's except for cropland $(\mathrm{CRO}, \mathrm{F}=-0.63 ; \mathrm{p}=0.53)$ and open shrubland $(\mathrm{OSH}, \mathrm{F}=-1,27 ; \mathrm{p}=0.21)$

\subsection{Performance of SGSMODIS and SGS in-situ $_{\text {to }}$ predict SGS NEE}

SGS estimates derived from MODIS VI's correlate better with SGS $_{\text {NEE }}$ than those derived from in-situ VI's (Fig. 2 and 3; Table 5). SGS MODIS-NDVI dates show the highest correlation coefficient $\left(\mathrm{R}^{2}=0.77\right.$ and $\left.\mathrm{R}^{2}=0.65\right)$. The $\mathrm{SGS}_{\text {MODIS-NDVI }}$ prediction occurs at a point in time, $21-22$ days earlier than that of NEE (i.e. $\mathrm{SGS}_{\mathrm{NEE}}$ ). In contrast, the $\mathrm{SGS}_{\text {in-situ-NDVI }}$ date occurs $25-26$ days earlier than that of $\mathrm{SGS}_{\mathrm{NEE}}$ (see Table 5).

Non-significant correlations are found for the other in-situ VI's (except for the NDVI). Though the SGS dates derived from the MODIS WRDVI performs satisfactory as well $\left(\right.$ Table $5 ; \mathrm{R}^{2}=$ 0.70). It predicts SGS dates 23-24 days earlier than the $\mathrm{SGS}_{\mathrm{NEE}}$ dates. GEMI shows the poorest correlations (see Table 5).

For many PFT's, SGS $S_{\text {NEE }}$ shows a higher correlation coefficient value with SGS $_{\text {MODIS }}$ than with

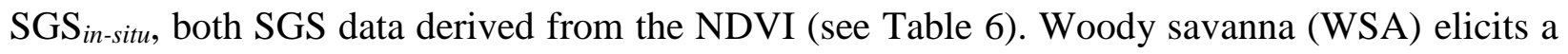
very good correlation between $\mathrm{SGS}_{\mathrm{NEE}}$ and $\mathrm{SGS} \mathrm{S}_{\mathrm{MODIS}-\mathrm{NDVI}}$ and $\mathrm{SGS}_{\text {in-situ-NDVI }}$ (see Table 6). Nevertheless, only one site has been used for this PFT.

Note however, that SGS MODIS-NDVI based estimates for deciduous forest $\left(\right.$ Table $6: \mathrm{DBF} ; \mathrm{R}^{2}=$ 0.74) elicits a high correlation coefficient. Moreover, the SGS MODIS-NDVI date is only only 8-9 days earlier than $\mathrm{SGS}_{\mathrm{NEE}}$. 


\section{[Figure 2]}

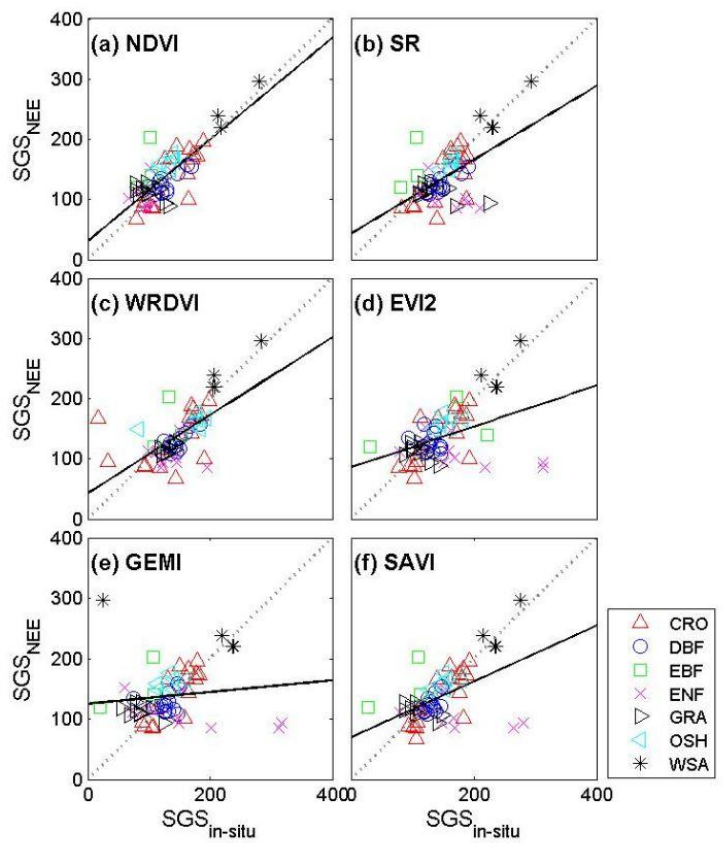

Figure 2 - Relationships between the start day of the growing season, derived from in-situ $\left(\right.$ SGS $\left._{\text {in-situ }}\right)$ VI's (see VI definitions in Table 2) and NEE (SGS NEE$_{\text {) }}$ for the different PFT's considered in this paper. Black lines represent linear interpolation functions (for all PFT's pooled), dotted lines 1:1 relationships. 


\section{[Figure 3]}

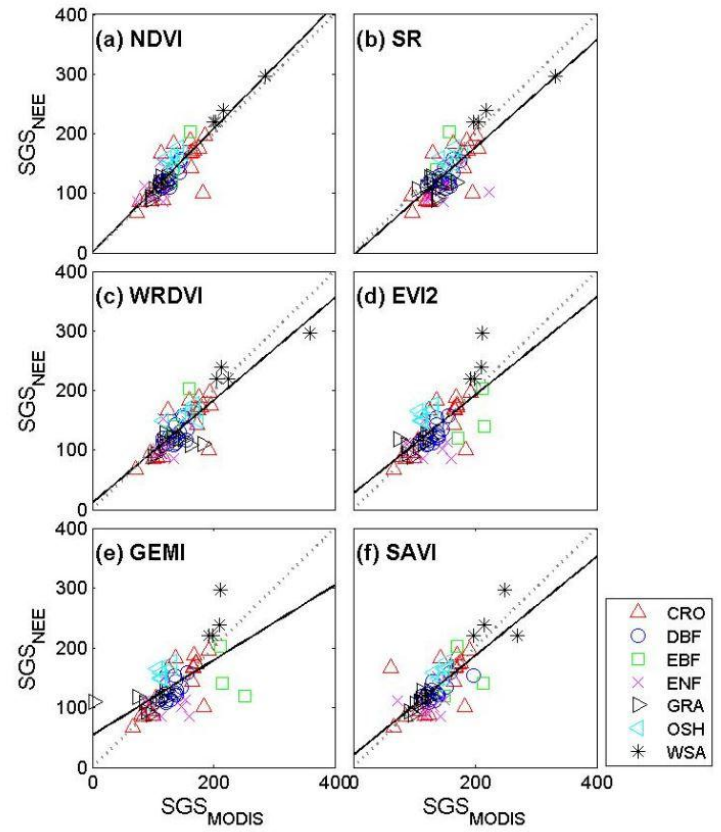

Figure 3 - Relationships between the day of the start of a growing season as derived from

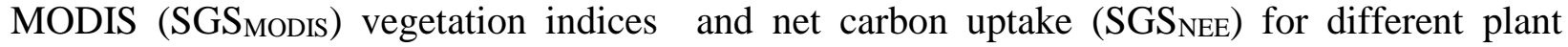
functional types as in Fig. 2, except that the start of the growing season day is derived from MODIS vegetation indices (SGSMODIS) instead of in-situ vegetation indices. 


\section{[Table 5]}

Table 5 - Statistics of correlation analysis between the day of the start of the growing season (SGS) derived from NEE (SGS NEE$_{\text {) }}$ and SGS derived from MODIS (SGS MODIS $_{\text {) }}$ and in-situ $\left(\mathrm{SGS}_{\text {in-situ }}\right)$ VI's (see definition in Tab. 2), and net carbon uptake ( $\left.\mathrm{SGS}_{\mathrm{NEE}}\right)$, for all PFT's, pooled. N. obs—number of available sites and years; $R^{2}$ —coefficient of determination; RMSE—root mean square error; $\mathrm{NMB}$-normalized mean bias; Y-int—y-intercept of the linear model; Slope-slope of the linear model; $\mathrm{R}_{\mathrm{cv}}{ }^{2}$ - cross-validate coefficient of determination; and $\mathrm{RMSE}_{\mathrm{c} v}-$ cross-validated root mean square error. Bold letters indicate the model with highest $\mathrm{R}^{2}$ value.

\begin{tabular}{|c|c|c|c|c|c|c|c|c|}
\hline & N. obs & $\begin{array}{l}\mathrm{R}^{2} \\
(-)\end{array}$ & $\begin{array}{c}\text { RMSE } \\
\text { (day) }\end{array}$ & $\begin{array}{l}\text { NMB } \\
\text { (day) }\end{array}$ & $\begin{array}{l}\text { Y-int } \\
\text { (day) }\end{array}$ & $\begin{array}{c}\text { Slope } \\
(-)\end{array}$ & $\begin{array}{c}\mathrm{R}_{\mathrm{cv}}{ }^{2} \\
(-)\end{array}$ & $\begin{array}{c}\mathrm{RMSE}_{\mathrm{c}} \\
\text { (day) }\end{array}$ \\
\hline \multicolumn{9}{|c|}{ SGS $_{\text {NEE }}$ vs. SGS $S_{\text {MODIS }}$} \\
\hline NDVI & 64 & $0.77 *$ & 20.50 & 0.0006 & 0.38 & 1.04 & 0.77 & 20.47 \\
\hline SR & 64 & $0.59 *$ & 27.43 & -0.0020 & -4.50 & 0.90 & 0.59 & 27.44 \\
\hline WRDVI & 64 & $0.70 *$ & 23.58 & -0.0010 & 11.06 & 0.86 & 0.70 & 23.60 \\
\hline EVI2 & 64 & $0.51 *$ & 30.04 & 0.0004 & 26.82 & 0.82 & 0.51 & 30.14 \\
\hline GEMI & 63 & $0.40 *$ & 33.47 & 0.0005 & 53.49 & 0.63 & 0.39 & 33.54 \\
\hline SAVI & 64 & $0.58^{*}$ & 27.76 & -0.0004 & 20.33 & 0.83 & 0.58 & 27.85 \\
\hline \multicolumn{9}{|c|}{ SGS $_{\text {NEE }}$ vs. SGS $S_{i n-s i t u}$} \\
\hline NDVI & 64 & $0.65^{*}$ & 25.23 & 0.0014 & 30.35 & 0.84 & 0.65 & 25.23 \\
\hline SR & 64 & $0.32 *$ & 35.20 & -0.0016 & 42.99 & 0.61 & 0.32 & 35.12 \\
\hline WRDVI & 62 & $0.40^{*}$ & 33.08 & -0.0010 & 42.75 & 0.65 & 0.39 & 33.12 \\
\hline EVI2 & 64 & $0.18 *$ & 38.82 & -0.0013 & 85.66 & 0.34 & 0.18 & 38.88 \\
\hline GEMI & 62 & 0.02 & 41.74 & 0.0007 & 125.09 & 0.10 & 0.02 & 41.50 \\
\hline SAVI & 62 & $0.26^{*}$ & 36.92 & -0.0009 & 69.75 & 0.46 & 0.26 & 36.94 \\
\hline
\end{tabular}




\section{[Table 6]}

Table 6 - Correlation between the start day of the growing season (SGS) derived from NEE (SGS $\mathrm{NEE}_{\text {) }}$ and derived from MODIS (SGS MODIS) respectively in-situ $\left(\mathrm{SGS}_{\text {in-situ }}\right)$ NDVI's. PFTplant functional type; $N$. obs-number of available sites and years; $R^{2}$-coefficient of determination; RMSE—root mean square error; NMB—normalized mean bias; Y-int-yintercept of the linear model; Slope-slope of the linear model; $\mathrm{R}_{\mathrm{cv}}{ }^{2}$-cross-validate coefficient of determination; and RMSE $\mathrm{c}_{\mathrm{c}}$ cross-validated root mean square error. Bold letters indicate the model with highest $\mathrm{R}^{2}$ value.

\begin{tabular}{|c|c|c|c|c|c|c|c|c|}
\hline PFT & N.obs & $\begin{array}{l}\mathrm{R}^{2} \\
(-)\end{array}$ & $\begin{array}{c}\text { RMSE } \\
\text { (day) }\end{array}$ & $\begin{array}{r}\text { NMB } \\
\text { (day) }\end{array}$ & $\begin{array}{l}\text { Y-int } \\
\text { (day) }\end{array}$ & $\begin{array}{c}\text { Slope } \\
(-)\end{array}$ & $\begin{array}{c}\mathrm{R}_{\mathrm{cv}}{ }^{2} \\
(-)\end{array}$ & $\begin{array}{c}\mathrm{RMSE}_{\mathrm{cv}} \\
\text { (day) }\end{array}$ \\
\hline \multicolumn{9}{|c|}{ SGS $_{\text {MODIS }}$ derived from NDVI } \\
\hline CRO & 16 & $0.54^{*}$ & 31.24 & 0.0009 & 22.61 & 0.85 & 0.53 & 31.65 \\
\hline DBF & 15 & $0.74 *$ & 8.02 & 0.0006 & -13.89 & 1.10 & 0.74 & 8.03 \\
\hline EBF & 3 & 0.96 & 11.44 & 0.0307 & $\begin{array}{c}- \\
185.23\end{array}$ & 2.40 & 1.00 & 0.00 \\
\hline ENF & 10 & 0.23 & 21.88 & 0.0041 & 36.18 & 0.70 & 0.24 & 21.90 \\
\hline GRA & 10 & $0.59 *$ & 8.69 & 0.0007 & 7.99 & 0.93 & 0.57 & 8.73 \\
\hline OSH & 6 & 0.37 & 9.49 & 0.0335 & 77.85 & 0.62 & 0.40 & 9.62 \\
\hline WSA & 4 & $0.99 *$ & 3.75 & 0.0198 & 38.75 & 0.91 & 0.94 & 4.42 \\
\hline \multicolumn{9}{|c|}{ SGS $_{i n \text {-situ }}$ derived from NDVI } \\
\hline CRO & 16 & $0.65^{*}$ & 27.17 & 0.0001 & 1.09 & 0.99 & 0.66 & 26.22 \\
\hline DBF & 15 & $0.60 *$ & 10.00 & 0.0003 & 52.13 & 0.59 & 0.63 & 9.96 \\
\hline EBF & 3 & 0.45 & 45.26 & 0.2063 & -61.39 & 2.26 & 1.00 & 0.00 \\
\hline ENF & 10 & 0.17 & 22.77 & 0.0163 & 63.46 & 0.49 & 0.16 & 22.81 \\
\hline GRA & 10 & $0.49 *$ & 9.64 & 0.0124 & 156.10 & -0.45 & 0.52 & 9.57 \\
\hline OSH & 6 & 0.34 & 9.70 & 0.0376 & 96.24 & 0.49 & 0.28 & 10.38 \\
\hline WSA & 4 & 0.91 & 13.59 & 0.0128 & -1.31 & 1.06 & 1.00 & 0.00 \\
\hline
\end{tabular}




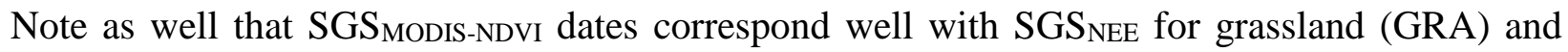
cropland (CRO). However, $\mathrm{SGS}_{\text {in-situ-NDVI }}$ shows a higher $\mathrm{R}^{2}$ and lower RMSE than SGS NDVI for cropland. For cropland the MODIS WRDVI, EVI2 and GEMI show slighly higher scores than the NDVI (see Table S3 and S4 in the Supplementary Data).

For grassland it is interesting to note that $\mathrm{SGS}_{\mathrm{MODIS}}$ and $\mathrm{SGS}_{\text {in-situ }}$ are better correlated with

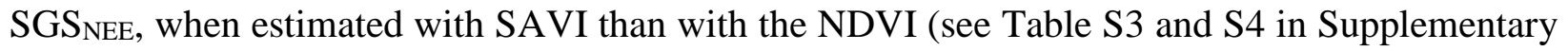
Data).

\section{GLMM analysis}

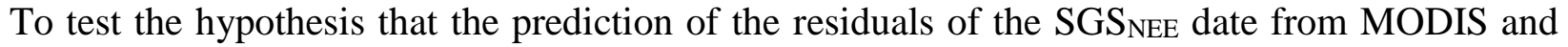
in-situ VI's (i.e. $\mathrm{SGS}_{\mathrm{NEE}}-\mathrm{SGS}_{\mathrm{MODIS}}$ and $\mathrm{SGS}_{\mathrm{NEE}}-\mathrm{SGS}_{\text {in-situ}}$, respectively) are related to VI seasonality, VI, PFT type and the variable amplitude (the difference between the maximum and minimum value of a VI), a GLMM analysis was performed.

The results of the GLMM analysis of the residuals of the regression line between SGS $_{\mathrm{NEE}}$ and $\mathrm{SGS}_{\text {MODIS }}$ reveals significant two way interactions between each of the three explanatory variables (see Table 7). For in-situ data only the interaction effect PFT x VI significantly affects the residuals of the $\mathrm{SGS}_{\mathrm{NEE}}$ vs. SGS in-situ relationship. The other interctions were not significant and therefore they were not taken into account in the final model $\left(\mathrm{amp} * \mathrm{VI}: \mathrm{F}_{5,285}=0.78, \mathrm{p}=\right.$ 0.57; amp*PFT: $\left.\mathrm{F}_{6,290}=1.03, \mathrm{p}=0.41\right)$.

\section{[Table 7]}


Table 7 - Results of a GLMM analysis testing the sensitivity of the residuals of a regression line

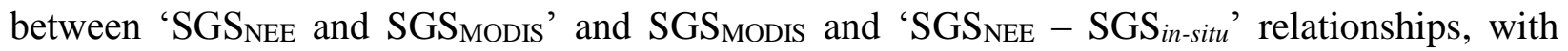
respect to PFT's and VI's and amplitude (amp). Effect-fixed effect in the LME; Num DFNumerator degree of freedom; Den DF-Denominator degree of freedom; F Value — value of statistics; PFT—plant functional type; $\mathrm{p}$ - probability; VI-vegetation index; and ampdifference between the maximum and minimum value of a VI.

\begin{tabular}{|c|c|c|c|c|}
\hline Effect & Num DF & Den DF & F Value & $\mathrm{p}$ \\
\hline \multicolumn{5}{|c|}{$\mathrm{SGS}_{\mathrm{NEE}}-\mathrm{SGS}_{\mathrm{MODIS}}$} \\
\hline amp & 1 & 282 & 11.63 & 0.001 \\
\hline VI & 5 & 282 & 0.67 & 0.646 \\
\hline PFT & 6 & 282 & 3.98 & 0.001 \\
\hline amp*PFT & 6 & 282 & 3.69 & 0.001 \\
\hline amp*VI & 5 & 282 & 3.29 & 0.006 \\
\hline $\mathrm{PFT}^{*} \mathrm{VI}$ & 30 & 282 & 4.22 & $<.0001$ \\
\hline \multicolumn{5}{|c|}{$\mathrm{SGS}_{\mathrm{NEE}}-\mathrm{SGS}_{i n-s i t u}$} \\
\hline amp & 1 & 296 & 0.41 & 0.522 \\
\hline VI & 5 & 296 & 11.35 & $<.0001$ \\
\hline PFT & 6 & 296 & 2.48 & 0.023 \\
\hline PFT*VI & 30 & 296 & 3.68 & $<.0001$ \\
\hline
\end{tabular}

Figure 4 reports on the variation (e.g. mean value and standard error) of the SGS date estimates using three different methods (i.e. (a) derived from NEE flux data, (b) derived from in-situ 
fAPAR and (c) derived from MODIS EVI) for cropland, deciduous broadleaf forest and (c) evergreen needleleaf forest sites reported in table S1 in the Supplementary Data.

Deciduous forest (DBF) shows a good agreement between the three methods. SGS date estimates based on remote sensing are however uncertain for evergreen needle leaf forest (ENF). Moreover, EVI predicts the SGS date at an earlier point in time than NEE and in-situ fAPAR.

\section{[Figure 4]}

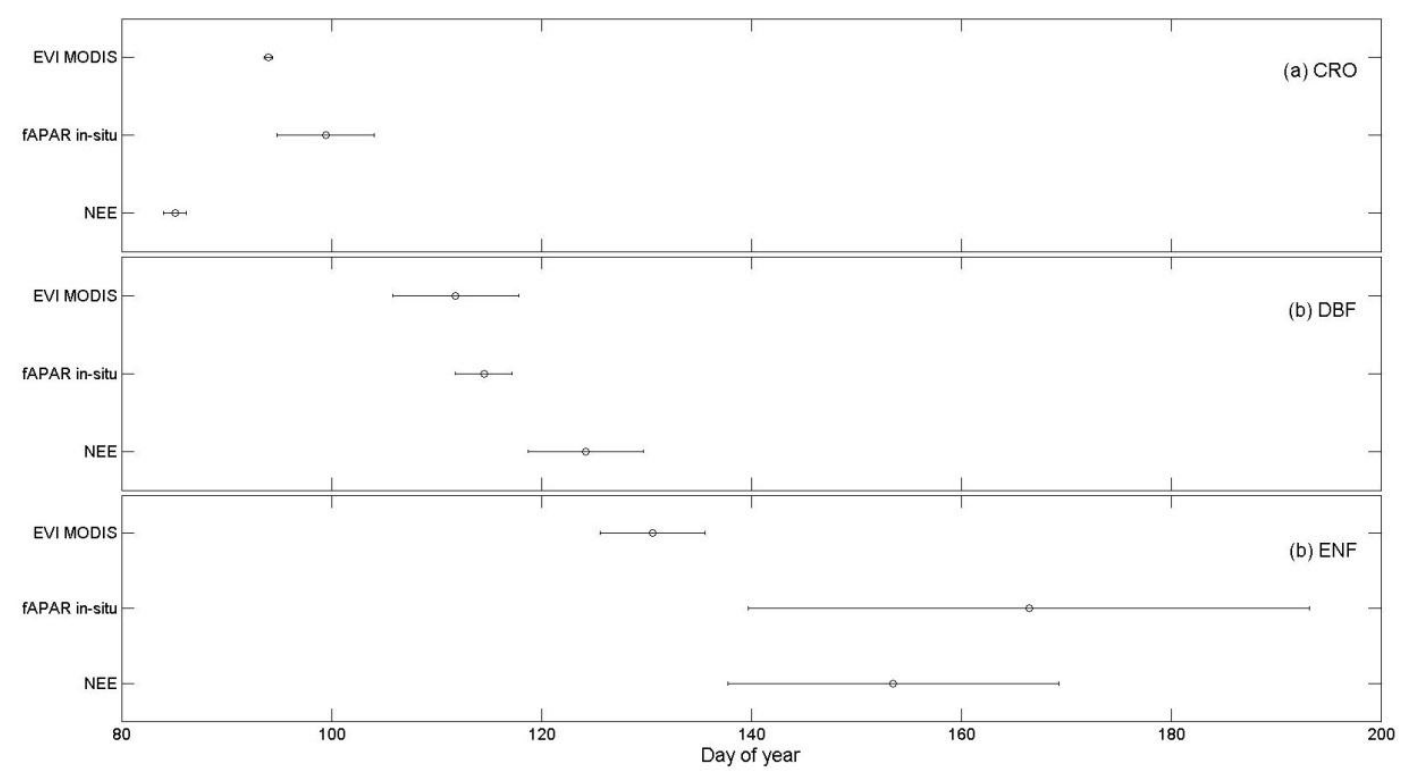

Figure 4 - Start of growing season (SGS) date estimated by using three methods. NEE is mass flux data measured at flux sites, fAPAR in-situ is fAPAR derived from in-situ radiation measurements and EVI MODIS is EVI derived from MODIS data for (a) CRO—Cropland, (b) DBF_-Deciduous Broadleaf Forest, and (c) ENF_-Evergreen Needle-leaf Forest sites locate in 
the Northern Hemisphere. Dots represent mean values of SGS date estimates for the three cited variables variable and lines represent data standard errors.

\section{Discussion}

\subsection{Phenological metrics of in-situ and satellite sensor acquisitions for different VI's and PFT's}

Typically, MODIS VI's tend to predict the SGS date at an earlier time point in the season than compared with the in-situ VI's (Figs. 1 and 2; Table 3). The disagreement between MODIS and the in-situ VI's can be related to the different sensor characteristics, e.g. the different spectral bandwidths (hence, different spectral resolutions) and instantaneous fields of view (IFOV's). The latter depends on the distance between the canopy and the sensor position and field of view angle. All VI's considered in this paper are computed using RED and NIR reflectances (see Table 2) from MODIS and in-situ acquisitions for 28 FLUXNET sites (Table 1). In that respect in-situ RED and NIR reflectances are acquired with two extremely broad spectral bands (400 to $700 \mathrm{~nm}$ and 700 to $2800 \mathrm{~nm}$, respectively). Wilson and Meyers (2007) report that a steep increase of insitu VI's based on these broad RED and NIR bands indicates an increase of canopy greening and/or vegetation cover at the canopy level. On the other hand, the MODIS sensor has a higher spectral resolution than the in-situ pyranometers. Typically, the MODIS RED and NIR spectral bandwidths span a spectral range from 620 to $670 \mathrm{~nm}$ and 841 to $876 \mathrm{~nm}$ respectively. This difference in spectral resolution contributes to a difference in interpretation of the canopy biophysical properties for a growing season, e.g. photosynthetic rate (Inoue et al. 2008).

In addition, during greening, canopy reflectance in the PAR region (PAR ranges from 400 to $700 \mathrm{~nm}$ ) decreases due to an increase in PAR absorption by additional chlorophyll (and 
photosynthesis) in the canopy due to new, emerging leaves (Ryu et al. 2008). Moreover, the spectral signature of upwelling optical radiation in many PFT's changes due to a decreasing gap fraction when time in the growing season progresses. Clearly, this is an issue of strong concern and interest. NIR has a higher transmissivity in the canopy than RED and hence NIR reflectance changes with canopy structure and largely opposite with respect to the PAR band (Ollinger et al. 2008).

Another issue to be mentioned is the difference in IFOV for MODIS and the in-situ observations. The IFOV of a sensor and its orbit or acquisition position determines the surface area covered by the sensor. A large difference exists between respectively the MODIS and the in-situ IFOV's. No need to state that this does affect comparability of top-of-the-canopy reflectance and hence the derived VI values for both sensor types (i.e., MODIS and in-situ). The area acquired by MODIS is 500 x $500 \mathrm{~m}$ per pixel, e.g. $250,000 \mathrm{~m}^{2}$. This a much larger surface area covered than with a flux tower mounted sensor, even when this camera has a large IFOV, because flux towers do not exceed canopy height very significantly. This brings up the issue of the differences in tower and canopy height, between the different flux tower sites. The different sites have fundamentally different IFOV's for the for in-situ observations except when corrected for by sensor fore-optics, so that a match between the MODIS IFOV and the tower sensor IFOV is obtained. This however is never the case for the FLUXNET sites as there is no standard procedure defined to guarantee a consistently equal IFOV. Typically, the in-situ sensors are positioned horizontally at 1 up to 10 $\mathrm{m}$ above the canopy top level and near the flux sensors (for more details see Balzarolo et al. (2011)). The remotely sensed response originating from MODIS top-of-the-canopy VI's has a IFOV of $120^{\circ}$ and a FOV of $250,000 \mathrm{~m}^{2}$. In the case of the tower sensors, the radiation reflected by the canopy originates from an IFOV of about $120^{\circ}$ as well. However, the maximum surface 
area observed by the in-situ sensor varies roughly between 5.44 and $54.41 \mathrm{~m}^{2}$, assuming the height of the sensor above the canopy varies between 1 to $10 \mathrm{~m}$. That's a difference in magnitude in FOV of about a factor 20,000, which is a difference of more than 5 orders of magnitude. These huge differences in FOV make the evaluation of MODIS data compared with in-situ measurements quite complex. Biophysical variables like gap fraction and LAI can be estimated relatively accurately close to the canopy, but much more difficult at a spatial resolution of $500 \times 500 \mathrm{~m}$, even for forest.

Site spatial heterogeneity can be estimated more accurately close to the top-of-the-canopy as opposed to spaceborne observations and dependant on the PFT considered (Cescatti et al. 2012).

Of all VI's investigated in this paper, the NDVI shows the highest correlation coefficient for the relationship between $\mathrm{SGS}_{\text {MODIS }}$ and $\mathrm{SGS}_{\text {in-situ }}$ (Fig. 1, Table 3), but with a 20-21 days earlier SGS date obtained for MODIS than for in-situ sensors. Furthermore, the SGSMODIS vs. SGS in-situ $_{\text {in }}$ relationship differs according to the VI considered.

The NDVI is strictly related to the transition region between RED and NIR (i.e. the red-edge region). The red-edge region is affected primarily, by leaf chlorophyll contentand at low LAI values by the spectral properties of the soil (or snow) as well. These boundary conditions determine the spectral signature of the canopy during the growing season. Several authors reported that the difference in spectral resolution between MODIS and in-situ sensors leads to different VI values, certainly when the spectral signature changes with increasing LAI during the growing season.

In general, most carbon balance research focusses on a comparison of the NDVI derived from MODIS and in-situ radiation measurements, mostly for validation purposes. However, Wilson and Meyers (2007) compared in-situ NDVI observations, derived from the same tower set-up's 
used in this study, with a $1 \times 1 \mathrm{~km} 16$ days composite MODIS NDVI. They reported that the MODIS VI values show slightly larger amplitude than the in-situ vegetation index values.

\subsection{An optimal remote sensing proxy to characterise $\mathrm{CO}_{2}$ mass flux phenology}

This paper describes that MODIS VI performance is more optimal as a remote sensing proxy for SGS $_{\text {NEE }}$ (Figs. 2a and 3a; Table 5) with the boundary condition, that PFT data are pooled. As discussed earlier, the differences in MODIS and in-situ sensor characteristics determine the final result for different VI's and, consequently, affect the day of the start of carbon uptake $\mathrm{SGS}_{\mathrm{NEE}}$ for the different PFT's. Xiao et al. (2008) reported that the discrepancies between NEE fluxes estimated with MODIS VI's and the actually measured NEE are strictly related to the spatial complexity of the ecosystems in the MODIS pixel area (e.g. $1 \mathrm{~km} \times 1 \mathrm{~km}$ ).

For instance, different plant species within the same eddy covariance footprint will vary in their contribution to the NEE making it difficult to predict the phenological cycle of an ecosystem as a whole (Ma et al. 2007). Fisher and Mustard (2007) reported that changes in MODIS NDVI at the beginning of the growing season are not in phase with plant carbon dynamics but rather plant biomass dynamics. Likewise, this study demonstrates that the in-situ NDVI, in addition to the MODIS NDVI, is more sensitive to biomass rather than to carbon dynamics. It has been established quite exhaustively by many authors that the NDVI is a proxy for fAPAR (and to some extent LAI) estimation. However, the NDVI is not sensitive to short-term changes (changes occurring in less than a week) in photosynthetic activity (Gamon et al. 1992; Gitelson 2004; Hmimina et al. 2014). In addition, several studies indicate that photosynthetic capacity does not reach its maximum during the greening phase. For instance, the lag between flux phenology $\left(\mathrm{SGS}_{\mathrm{NEE}}\right)$ and canopy greenness (SGS $\mathrm{MODIS}$ and $\mathrm{SGS}_{\text {in-situ }}$ ), as observed from the VI's can be explained by a difference in time lag between ecosystem photosynthetic capacity and leaf 
expansion during spring for beech trees (i.e. see Supplementary data, for the Hainich site as described in Knohl et al. (2003)). In addition, Morecroft et al. (2003) stated that the full photosynthetic capacity of Quercus robur leaves is reached 50 days after bud break. At the start of the season, when the canopy is developing, an increase in carbon uptake is typically associated with an increase in soil respiration, able to reduce NEE substantially (Xiao et al. 2008). The study of Ryu et al. (2014) compares MODIS and in-situ leaf-out observations with optical sensors (i.e. LED and LAI-2000 measurements). It reports that the MODIS NDVI is able to sense the signal of understory leaf-out obtained from in-situ observations for deciduous forest. In addition, another study showed that the MODIS NDVI predicts an earlier leaf-out than in-situ observations for overstory leaf-out (Ganguly et al. 2010). For a deciduous forest, the leaf-out phase of the understorey canopy tends to occur earlier than that of the overstory.

Our results agree well with previous results obtained for deciduous ecosystems. For these ecosystems, a strong dependence of photosynthetic activity on leaf area expansion and MODIS and in-situ VI patterns agree well with the dynamics of NEE (see Supplementary Data).In grassland ecosystems for instance, a low variation of MODIS and in-situ VI's partially reflects GPP and NEE seasonal variations. Wohlfahrt et al. (2010) demonstrated that in-situ NDVI can be a proxy for carbon fluxes at least for two temperate mountain grasslands in Austria. Furthermore, the good performance of MODIS and in-situ SAVI to predict the start day of carbon uptake for different types of cropland (Table S3 and S4 in Supplementary Data) may be related to the presence of bare soil or fallow / sparse vegetation affecting the spectral signature of the soil surface from a mixture of soil and vegetation to homogeneous vegetation during the course of the growing season. This is particularly true for grassland sites where at the beginning of the growing season, the grassland canopy is not fully developed and hence the gap fraction of 
the canopy is high (or the $f$ Cover very low). The presence of the additional factor L (see Table 2) for the RED reflectance in the denominator of the SAVI equation, makes the vegetation index less sensitive to soil darkening due to an increase in soil moisture. Therefore, the spatial distribution of the vegetation for grassland PFT's is assumed to play a major role in the determination of the start of the growing season and, hence the start of carbon dioxide uptake.

For croplands we found that the MODIS WDRVI elicits a higher correlation coefficient value than the NDVI (Table S2 in Supplementary Data). This is a confirmation that the WRDVI is a good proxy for cropland phenology (Gitelson et al., 2004).

For evergreen broadleaf forests we didn't find high enough significant correlation coefficient values any more (Table 6). Typically all evergreen broadleaf sites described in this paper are located in tropical regions and characterised by a high and relatively constant photosynthetic and carbon activity over an entire year. Seasonal variations in carbon balance have been described (e.g. Bonal et al. (2008)), but this variation is clearly not reflected by MODIS and in situ NDVI's (Hmimina et al. 2013) and certainly not comparable with temperate zone PFT carbon dynamics variability.

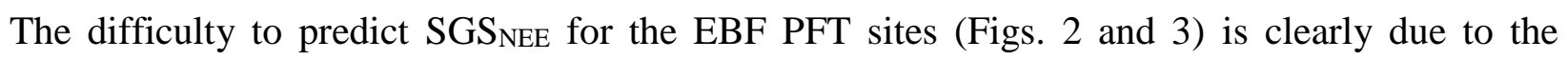
discrepancy between canopy physiology and phenology. Canopy phenology remains rather stable (Hilker et al. 2014), whereas canopy physiology depends on seasonal variations in environmental factors (mainly radiation and soil water availability, especially in monsoon forced ecosystems) (Monson et al. 2005). In addition, for tropical regions long rainy seasons make it difficult to collect both in-situ measurements and clear-sky satellite imagery (Hmimina et al. 2013). 
Also for evergreen needleleaf forest significant correlations were not found. The annual phenological cycle of evergreen needle leaf boreal forests in Sweden is related more to snow and snow melt, than changes in needle canopy greening dynamics (Jönsson et al. 2010). For evergreen needleleaf forests, changes in greenness at the start of the growing season are decoupled from the start of the carbon uptake season and hence ecosystem physiological activity (Zwiazek et al. 2001).

Finally, the amplitude (i.e. the difference between the maximum and minimum value of a VI for each growing season), VI type and PFT properties affect the residuals of the correlation function between SGS $_{\mathrm{NEE}}$ and $\mathrm{SGS}_{\mathrm{MODIS}}$. This suggests that differences in predicting $\mathrm{SGS}_{\mathrm{NEE}}$ with different VI's depends on amplitude differences for both carbon and VI dynamics. This suggests that it is not likely to develop a generic model for the description and modelling of flux phenology for all global PFT's and ecosystems. Even though the NDVI derived from both MODIS and in-situ data shows a good correlation for all PFTs, pooled (Tabs. 5-6), a VI for a PFT improves the estimation of the SGS date for a that specific PFT (e.g. the WRDVI for cropland for example). Therefore, further efforts should focus on the understanding of the most appropriate VI or a combination of different VI's or maybe even multi-dimensional hyperspectral VI's, which may have the capacity to describe the clearcut complexity of flux phenology (Wong and Gamon 2015).

\section{Conclusions}

MODIS and in-situ VI's show consistent results. Of all VI's considered in this paper, the NDVI shows the highest correlation coefficient for the relationship between the starting day of the growing season as observed with MODIS and in-situ observations. Also, the MODIS NDVI 
performs best when applied as an estimator for Net Ecosystem Exchange but only with the boundary condition that all PFT's are pooled. Nonetheless, it has been elicited that a specific VI can be applied to improve the estimation of a SGS date for a specific PFT - for example the WRDVI for cropland, which is however suboptimal for the other PFT's.

Summarizing, this study suggests that:

(i) In-situ radiation data measurements are a good approach to bridge the gap between local eddy covariance carbon fluxes and MODIS global VI acquisitions;

(ii) Methodological improvement and the use of hyperspectral optical sensors is required at the flux towers to better describe ecosystem carbon dynamics and carbon dioxide flux phenology (Porcar-Castell et al. 2015).

(iii) A generic model used to estimate flux phenology for all ecosystems is still a bottleneck issue, though multi-dimensional VI's as obtained from hyperspectral remote sensing are a good possibility to develop a generic model (Rivera et al. 2014).

(iv) Further work should explore the utility of the new forthcoming super-spectral 'Copernicus' Sentinel-2 and Sentinel-3 missions that will provide a vast data stream helpful to understand the physiological and photosynthetic activity of the canopy driven by seasonally changing pigment concentrations (e.g. chlorophylls) and fluorescence (Van Wittenberghe et al. 2013; Van Wittenberghe et al. 2014; Verrelst et al. 2015).

Finally, the work presented in this paper confirms the importance of ecosystem (top-of-thecanopy scale) remote sensing observations to better describe global ecosystem phenological metrics as well as to validate satellite VI's as upscaling proxies. In this regard, the establishment of long-term global monitoring networks such as ICOS (www.icos-infrastructure.eu) NEON (www.neoninc.org) and AmeriFlux (http://ameriflux.lbl.gov), foster the use of in-situ 
measurements and provide a unique framework for this type of activity, which may ultimately lead to more accurate estimates of the global terrestrial carbon balance.

\section{Acknowledgements}

This work used radiometric and eddy covariance measurements acquired by the FLUXNET community and in particular by the following networks: AmeriFlux (US Department of Energy, Biological and Environmental Research, Terrestrial Carbon Program (DE-FG02-04ER63917 and DE-FG02-04ER63911)), AfriFlux, AsiaFlux, CarboAfrica, CarboEuropeIP, CarboItaly, CarboMont, ChinaFlux, FLUXNET - Canada (supported by CFCAS, NSERC, BIOCAP, Environment Canada, and NRCan), GreenGrass, KoFlux, LBA, NECC, OzFlux, TCOS Siberia, and USCCC. We acknowledge the support to data harmonization provided by CarboEuropeIP, FAO-GTOS-TCO, iLEAPS (the Integrated Land Ecosystem-Atmosphere Processes Study, a core project of IGBP), Max Planck Institute for Biogeochemistry, National Science Foundation, University of Tuscia, Université Laval and Environment Canada and US Department of Energy and the database development and technical support from Berkeley Water Center, Lawrence Berkeley National Laboratory, Microsoft Research eScience, Oak Ridge National Laboratory, University of California - Berkeley, and University of Virginia. We would like to also acknowledge the PIs of the eddy covariance sites and all technicians, students, PhDs and postdocs for providing their data and support to FLUXNET network. The MODIS data used in this study are distributed by the Land Processes Distributed Active Archive Center (LP DAAC), located at the US Geological Survey (USGS) Earth Resources Observation and Science (EROS) Center (lpdaac.usgs.gov). I acknowledge the support from the Methusalem program of the Flemish Government. J. Peñuelas research was supported by the European Research Council 
Synergy grant ERC-2013-SyG-610028 IMBALANCE-P. Y. H. Fu was granted by Pegasus

Marie Curie Fellow. I thank my husband Nicola Arriga, PhD, for his invaluable help in understanding physics underlying radiation measurements and data processing. Lastly, we thank the anonymous referees and the editor for their constructive comments that improved this paper.

\section{References}

Baldocchi, D., Falge, E., Gu, L.H., Olson, R., Hollinger, D., Running, S., Anthoni, P., Bernhofer, C., Davis, K., Evans, R., Fuentes, J., Goldstein, A., Katul, G., Law, B., Lee, X.H., Malhi, Y., Meyers, T., Munger, W., Oechel, W., U, K.T.P., Pilegaard, K., Schmid, H.P., Valentini, R., Verma, S., Vesala, T., Wilson, K., \& Wofsy, S. (2001). FLUXNET: A new tool to study the temporal and spatial variability of ecosystem-scale carbon dioxide, water vapor, and energy flux densities. Bulletin of the American Meteorological Society, 82, 2415-2434

Baldocchi, D.D., Black, T.A., Curtis, P.S., Falge, E., Fuentes, J.D., Granier, A., Gu, L., Knohl, A., Pilegaard, K., Schmid, H.P., Valentini, R., Wilson, K., Wofsy, S., Xu, L., \& Yamamoto, S. (2005). Predicting the onset of net carbon uptake by deciduous forests with soil temperature and climate data: a synthesis of FLUXNET data. Int $\mathrm{J}$ Biometeorol, 49, 377-387

Balzarolo, M., Anderson, K., Nichol, C., Rossini, M., Vescovo, L., Arriga, N., Wohlfahrt, G., Calvet, J.C., Carrara, A., Cerasoli, S., Cogliati, S., Daumard, F., Eklundh, L., Elbers, J.A., Evrendilek, F., Handcock, R.N., Kaduk, J., Klumpp, K., Longdoz, B., Matteucci, G., Meroni, M., Montagnani, L., Ourcival, J.M., Sanchez-Canete, E.P., Pontailler, J.Y., Juszczak, R., Scholes, B., \& Martin, M.P. (2011). Ground-based optical measurements at European flux sites: a review of methods, instruments and current controversies. Sensors (Basel), 11, 7954-7981

Betancourt, J.L., Schwartz, M.D., Breshears, D.D., Cayan, D.R., Dettinger, M.D., Inouye, D.W., Post, E., \& Reed, B.C. (2005). Implementing a U.S. National Phenology Network. Eos, Transactions American Geophysical Union, 86, 539-539

Bonal, D., Bosc, A., Ponton, S., Goret, J.-Y., Burban, B., Gross, P., Bonnefond, J.-M., Elbers, J.A.N., Longdoz, B., Epron, D., Guehl, J.-M., \& Granier, A. (2008). Impact of severe dry season on net ecosystem exchange in the Neotropical rainforest of French Guiana. Glob Chang Biol, 14, 1917-1933

Cescatti, A., Marcolla, B., Santhana Vannan, S.K., Pan, J.Y., Román, M.O., Yang, X., Ciais, P., Cook, R.B., Law, B.E., Matteucci, G., Migliavacca, M., Moors, E., Richardson, A.D., Seufert, G., \& Schaaf, C.B. (2012). Intercomparison of MODIS albedo retrievals and in situ measurements across the global FLUXNET network. Remote Sensing of Environment, 121, 323-334 
Churkina, G., Schimel, D., Braswell, B.H., \& Xiao, X. (2005). Spatial analysis of growing season length control over net ecosystem exchange. Glob Chang Biol, 11, 1777-1787

Gamon, J.A., Peñuelas, J., \& Field, C.B. (1992). A narrow-waveband spectral index that tracks diurnal changes in photosynthetic efficiency. Remote Sensing of Environment, 41, 35-44

Ganguly, S., Friedl, M.A., Tan, B., Zhang, X., \& Verma, M. (2010). Land surface phenology from MODIS: Characterization of the Collection 5 global land cover dynamics product. Remote Sensing of Environment, 114, 1805-1816

Garrity, S.R., Bohrer, G., Maurer, K.D., Mueller, K.L., Vogel, C.S., \& Curtis, P.S. (2011). A comparison of multiple phenology data sources for estimating seasonal transitions in deciduous forest carbon exchange. Agricultural and Forest Meteorology, 151, 17411752

Gitelson, A.A. (2004). Wide Dynamic Range Vegetation Index for Remote Quantification of Biophysical Characteristics of Vegetation. Journal of Plant Physiology, 161, 165-173

Gitelson, A.A., Keydan, G.P., \& Merzlyak, M.N. (2006). Three-band model for noninvasive estimation of chlorophyll, carotenoids, and anthocyanin contents in higher plant leaves. Geophysical Research Letters, 33, L11402

Heinsch, F.A., Zhao, M., Running, S.W., Kimball, J.S., Nemani, R.R., Davis, K.J., Bolstad, P.V., Cook, B.D., Desai, A.R., \& Ricciuto, D.M. (2006). Evaluation of remote sensing based terrestrial productivity from MODIS using regional tower eddy flux network observations. Geoscience and Remote Sensing, IEEE Transactions on, 44, 1908-1925

Hilker, T., Lyapustin, A.I., Tucker, C.J., Hall, F.G., Myneni, R.B., Wang, Y., Bi, J., Mendes de Moura, Y., \& Sellers, P.J. (2014). Vegetation dynamics and rainfall sensitivity of the Amazon. Proceedings of the National Academy of Sciences, 111, 16041-16046

Hmimina, G., Dufrêne, E., Pontailler, J.Y., Delpierre, N., Aubinet, M., Caquet, B., de Grandcourt, A., Burban, B., Flechard, C., Granier, A., Gross, P., Heinesch, B., Longdoz, B., Moureaux, C., Ourcival, J.M., Rambal, S., Saint André, L., \& Soudani, K. (2013). Evaluation of the potential of MODIS satellite data to predict vegetation phenology in different biomes: An investigation using ground-based NDVI measurements. Remote Sensing of Environment, 132, 145-158

Hmimina, G., Dufrene, E., \& Soudani, K. (2014). Relationship between photochemical reflectance index and leaf ecophysiological and biochemical parameters under two different water statuses: towards a rapid and efficient correction method using real-time measurements. Plant Cell Environ, 37, 473-487

Huemmrich, K.F., Black, T.A., Jarvis, P.G., McCaughey, J.H., \& Hall, F.G. (1999). High temporal resolution NDVI phenology from micrometeorological radiation sensors. Journal of Geophysical Research: Atmospheres, 104, 27935-27944

Huete, A., Didan, K., Miura, T., Rodriguez, E.P., Gao, X., \& Ferreira, L.G. (2002). Overview of the radiometric and biophysical performance of the MODIS vegetation indices. Remote Sensing of Environment, 83, 195-213 
Huete, A.R. (1988). A soil-adjusted vegetation index (SAVI). Remote Sensing of Environment, 25, 295-309

Huete, A.R., Liu, H.Q., Batchily, K., \& van Leeuwen, W. (1997). A comparison of vegetation indices over a global set of TM images for EOS-MODIS. Remote Sensing of Environment, 59, 440-451

Inoue, Y., Peñuelas, J., Miyata, A., \& Mano, M. (2008). Normalized difference spectral indices for estimating photosynthetic efficiency and capacity at a canopy scale derived from hyperspectral and $\mathrm{CO} 2$ flux measurements in rice. Remote Sensing of Environment, 112, 156-172

Jenkins, J.P., Richardson, A.D., Braswell, B.H., Ollinger, S.V., Hollinger, D.Y., \& Smith, M.L. (2007). Refining light-use efficiency calculations for a deciduous forest canopy using simultaneous tower-based carbon flux and radiometric measurements. Agricultural and Forest Meteorology, 143, 64-79

Jiang, Z., Huete, A.R., Didan, K., \& Miura, T. (2008). Development of a two-band enhanced vegetation index without a blue band. Remote Sensing of Environment, 112, 3833-3845

Jönsson, A.M., Eklundh, L., Hellström, M., Bärring, L., \& Jönsson, P. (2010). Annual changes in MODIS vegetation indices of Swedish coniferous forests in relation to snow dynamics and tree phenology. Remote Sensing of Environment, 114, 2719-2730

Jonsson, P., \& Eklundh, L. (2002). Seasonality extraction by function fitting to timeseries of satellite sensor data. Geoscience and Remote Sensing, IEEE Transactions on, 40, 1824-1832

Jönsson, P., \& Eklundh, L. (2004). TIMESAT—a program for analyzing time-series of satellite sensor data. Computers \& Geosciences, 30, 833-845

Keenan, T.F., Gray, J., Friedl, M.A., Toomey, M., Bohrer, G., Hollinger, D.Y., Munger, J.W., O/'Keefe, J., Schmid, H.P., Wing, I.S., Yang, B., \& Richardson, A.D. (2014). Net carbon uptake has increased through warming-induced changes in temperate forest phenology. Nature Clim. Change, 4, 598-604

Knohl, A., Schulze, E.-D., Kolle, O., \& Buchmann, N. (2003). Large carbon uptake by an unmanaged 250-year-old deciduous forest in Central Germany. Agricultural and Forest Meteorology, 118, 151-167

Loveland, T.R., \& Belward, A.S. (1997). The IGBP-DIS global $1 \mathrm{~km}$ land cover data set, DISCover: First results. Int $J$ Remote Sens, 18, 3289-3295

Monson, R., Sparks, J., Rosenstiel, T., Scott-Denton, L., Huxman, T., Harley, P., Turnipseed, A., Burns, S., Backlund, B., \& Hu, J. (2005). Climatic influences on net ecosystem $\mathrm{CO} 2$ exchange during the transition from wintertime carbon source to springtime carbon sink in a high-elevation, subalpine forest. Oecologia, 146, 130-147

Morecroft, M.D., Stokes, V.J., \& Morison, J.I.L. (2003). Seasonal changes in the photosynthetic capacity of canopy oak (Quercus robur) leaves: the impact of slow development on annual carbon uptake. Int J Biometeorol, 47, 221-226 
Myneni, R.B., Hoffman, S., Knyazikhin, Y., Privette, J.L., Glassy, J., Tian, Y., Wang, Y., Song, X., Zhang, Y., Smith, G.R., Lotsch, A., Friedl, M., Morisette, J.T., Votava, P., Nemani, R.R., \& Running, S.W. (2002). Global products of vegetation leaf area and fraction absorbed PAR from year one of MODIS data. Remote Sensing of Environment, $83,214-231$

Nguy-Robertson, A., Gitelson, A., Peng, Y., Viña, A., Arkebauer, T., \& Rundquist, D. (2012). Green Leaf Area Index Estimation in Maize and Soybean: Combining Vegetation Indices to Achieve Maximal Sensitivity. Agron. J., 104, 1336-1347

Ollinger, S.V., Richardson, A.D., Martin, M.E., Hollinger, D.Y., Frolking, S.E., Reich, P.B., Plourde, L.C., Katul, G.G., Munger, J.W., Oren, R., Smith, M.L., Paw, U.K., Bolstad, P.V., Cook, B.D., Day, M.C., Martin, T.A., Monson, R.K., \& Schmid, H.P. (2008). Canopy nitrogen, carbon assimilation, and albedo in temperate and boreal forests: Functional relations and potential climate feedbacks. Proc Natl Acad Sci U S A, 105, 19336-19341

Papale, D., Reichstein, M., Aubinet, M., Canfora, E., Bernhofer, C., Kutsch, W., Longdoz, B., Rambal, S., Valentini, R., Vesala, T., \& Yakir, D. (2006). Towards a standardized processing of Net Ecosystem Exchange measured with eddy covariance technique: algorithms and uncertainty estimation. Biogeosciences, 3, 571-583

Peng, S., Piao, S., Ciais, P., Myneni, R.B., Chen, A., Chevallier, F., Dolman, A.J., Janssens, I.A., Penuelas, J., Zhang, G., Vicca, S., Wan, S., Wang, S., \& Zeng, H. (2013). Asymmetric effects of daytime and night-time warming on Northern Hemisphere vegetation. Nature, 501, 88-92

Petach, A.R., Toomey, M., Aubrecht, D.M., \& Richardson, A.D. (2014). Monitoring vegetation phenology using an infrared-enabled security camera. Agricultural and Forest Meteorology, 195-196, 143-151

Piao, S., Fang, J., Zhou, L., Ciais, P., \& Zhu, B. (2006). Variations in satellite-derived phenology in China's temperate vegetation. Glob Chang Biol, 12, 672-685

Piao, S., Tan, J., Chen, A., Fu, Y.H., Ciais, P., Liu, Q., Janssens, I.A., Vicca, S., Zeng, Z., Jeong, S.-J., Li, Y., Myneni, R.B., Peng, S., Shen, M., \& Penuelas, J. (2015). Leaf onset in the northern hemisphere triggered by daytime temperature. Nat Commun, 6

Porcar-Castell, A., Mac Arthur, A., Rossini, M., Eklundh, L., Pacheco-Labrador, J., Anderson, K., Balzarolo, M., Martín, M., Jin, H., \& Tomelleri, E. (2015). EUROSPEC: at the interface between remote sensing and ecosystem $\mathrm{CO} 2$ flux measurements in Europe. Biogeosciences Discuss, 12, 13069-13121

Reed, B.C., Brown, J.F., VanderZee, D., Loveland, T.R., Merchant, J.W., \& Ohlen, D.O. (1994). Measuring phenological variability from satellite imagery. Journal of Vegetation Science, 5, 703-714

Reichstein, M., Falge, E., Baldocchi, D., Papale, D., Aubinet, M., Berbigier, P., Bernhofer, C., Buchmann, N., Gilmanov, T., Granier, A., Grünwald, T., Havránková, K., Ilvesniemi, H., Janous, D., Knohl, A., Laurila, T., Lohila, A., Loustau, D., Matteucci, G., Meyers, T., Miglietta, F., Ourcival, J.-M., Pumpanen, J., Rambal, S., Rotenberg, E., Sanz, M., Tenhunen, J., Seufert, G., Vaccari, F., Vesala, T., Yakir, D., \& Valentini, R. 
(2005). On the separation of net ecosystem exchange into assimilation and ecosystem respiration: review and improved algorithm. Glob Chang Biol, 11, 1424-1439

Richardson, A.D., Black, T.A., Ciais, P., Delbart, N., Friedl, M.A., Gobron, N., Hollinger, D.Y., Kutsch, W.L., Longdoz, B., Luyssaert, S., Migliavacca, M., Montagnani, L., Munger, J.W., Moors, E., Piao, S., Rebmann, C., Reichstein, M., Saigusa, N., Tomelleri, E., Vargas, R., \& Varlagin, A. (2010). Influence of spring and autumn phenological transitions on forest ecosystem productivity. Philos Trans $R$ Soc Lond B Biol Sci, 365, 3227-3246

Richardson, A.D., Braswell, B.H., Hollinger, D.Y., Jenkins, J.P., \& Ollinger, S.V. (2009). Near-surface remote sensing of spatial and temporal variation in canopy phenology. Ecol Appl, 19, 1417-1428

Rivera, J., Verrelst, J., Delegido, J., Veroustraete, F., \& Moreno, J. (2014). On the SemiAutomatic Retrieval of Biophysical Parameters Based on Spectral Index Optimization. Remote Sensing, 6, 4927

Ryu, Y., Baldocchi, D.D., Ma, S., \& Hehn, T. (2008). Interannual variability of evapotranspiration and energy exchange over an annual grassland in California. Journal of Geophysical Research: Atmospheres, 113, D09104

Ryu, Y., Lee, G., Jeon, S., Song, Y., \& Kimm, H. (2014). Monitoring multi-layer canopy spring phenology of temperate deciduous and evergreen forests using low-cost spectral sensors. Remote Sensing of Environment, 149, 227-238

Sakamoto, T., Wardlow, B.D., Gitelson, A.A., Verma, S.B., Suyker, A.E., \& Arkebauer, T.J. (2010). A Two-Step Filtering approach for detecting maize and soybean phenology with time-series MODIS data. Remote Sensing of Environment, 114, 2146-2159

Schmid, H.P. (2002). Footprint modeling for vegetation atmosphere exchange studies: a review and perspective. Agricultural and Forest Meteorology, 113, 159-183

Tucker, C.J. (1979). Red and photographic infrared linear combinations for monitoring vegetation. Remote Sensing of Environment, 8, 127-150

Van Wittenberghe, S., Alonso, L., Verrelst, J., Hermans, I., Delegido, J., Veroustraete, F., Valcke, R., Moreno, J., \& Samson, R. (2013). Upward and downward solar-induced chlorophyll fluorescence yield indices of four tree species as indicators of traffic pollution in Valencia. Environmental Pollution, 173, 29-37

Van Wittenberghe, S., Alonso, L., Verrelst, J., Hermans, I., Valcke, R., Veroustraete, F., Moreno, J., \& Samson, R. (2014). A field study on solar-induced chlorophyll fluorescence and pigment parameters along a vertical canopy gradient of four tree species in an urban environment. Science of the Total Environment, 466, 185-194

Verma, M., Friedl, M.A., Richardson, A.D., Kiely, G., Cescatti, A., Law, B.E., Wohlfahrt, G., Gielen, B., Roupsard, O., Moors, E.J., Toscano, P., Vaccari, F.P., Gianelle, D., Bohrer, G., Varlagin, A., Buchmann, N., van Gorsel, E., Montagnani, L., \& Propastin, P. (2014). Remote sensing of annual terrestrial gross primary productivity from MODIS: an assessment using the FLUXNET La Thuile data set. Biogeosciences, 11, 2185-2200 
Verrelst, J., Camps-Valls, G., Muñoz-Marí, J., Rivera, J.P., Veroustraete, F., Clevers, J.G., \& Moreno, J. (2015). Optical remote sensing and the retrieval of terrestrial vegetation bio-geophysical properties-A review. ISPRS Journal of Photogrammetry and Remote Sensing, 108, 273-290

Viña, A., Gitelson, A.A., Nguy-Robertson, A.L., \& Peng, Y. (2011). Comparison of different vegetation indices for the remote assessment of green leaf area index of crops. Remote Sensing of Environment, 115, 3468-3478

Walker, J.J., de Beurs, K.M., \& Wynne, R.H. (2014). Dryland vegetation phenology across an elevation gradient in Arizona, USA, investigated with fused MODIS and Landsat data. Remote Sensing of Environment, 144, 85-97

Wang, Y., Woodcock, C.E., Buermann, W., Stenberg, P., Voipio, P., Smolander, H., Häme, T., Tian, Y., Hu, J., Knyazikhin, Y., \& Myneni, R.B. (2004). Evaluation of the MODIS LAI algorithm at a coniferous forest site in Finland. Remote Sensing of Environment, 91, 114-127

Wilson, T.B., \& Meyers, T.P. (2007). Determining vegetation indices from solar and photosynthetically active radiation fluxes. Agricultural and Forest Meteorology, 144, 160-179

Wohlfahrt, G., Pilloni, S., Hörtnagl, L., \& Hammerle, A. (2010). Estimating carbon dioxide fluxes from temperate mountain grasslands using broad-band vegetation indices. Biogeosciences (Online), 7, doi:10.5194/bg-5197-5683-2010

Wong, C., \& Gamon, J.A. (2015). The photochemical reflectance index provides an optical indicator of spring photosynthetic activation in evergreen conifers. New Phytologist, 206, 196-208

Wu, W. (2014). The Generalized Difference Vegetation Index (GDVI) for Dryland Characterization. Remote Sensing, 6, 1211-1233

Xiao, J., Zhuang, Q., Baldocchi, D.D., Law, B.E., Richardson, A.D., Chen, J., Oren, R., Starr, G., Noormets, A., Ma, S., Verma, S.B., Wharton, S., Wofsy, S.C., Bolstad, P.V., Burns, S.P., Cook, D.R., Curtis, P.S., Drake, B.G., Falk, M., Fischer, M.L., Foster, D.R., Gu, L., Hadley, J.L., Hollinger, D.Y., Katul, G.G., Litvak, M., Martin, T.A., Matamala, R., McNulty, S., Meyers, T.P., Monson, R.K., Munger, J.W., Oechel, W.C., Paw U, K.T., Schmid, H.P., Scott, R.L., Sun, G., Suyker, A.E., \& Torn, M.S. (2008). Estimation of net ecosystem carbon exchange for the conterminous United States by combining MODIS and AmeriFlux data. Agricultural and Forest Meteorology, 148, 1827-1847

Yang, Q., Fu, Q., \& Hu, Y. (2010). Radiative impacts of clouds in the tropical tropopause layer. Journal of Geophysical Research: Atmospheres, 115, D00H12

Zhang, X., Friedl, M.A., Schaaf, C.B., Strahler, A.H., Hodges, J.C.F., Gao, F., Reed, B.C., \& Huete, A. (2003). Monitoring vegetation phenology using MODIS. Remote Sensing of Environment, 84, 471-475

Zwiazek, J., Renault, S., Croser, C., Hansen, J., \& Beck, E. (2001). Biochemical and Biophysical Changes in Relation to Cold Hardiness. In F. Bigras, \& S. Colombo (Eds.), Conifer Cold Hardiness (pp. 165-186): Springer Netherlands 


\section{List of Figure Captions}

Figure 1 - Relationship between the start day of a growing season $\left(\mathrm{SGS}_{i n-\text { situ }}\right.$ ) as derived from insitu and MODIS (SGS MODIS) VI's (see VI definitions in Table 2) for different PFT's (CROCropland; DBF-Deciduous Broadleaf Forest; EBF-Evergreen Broadleaf Forest; ENFEvergreen Needle-leaf Forest; GRA-Grassland; OSH-Open Shrubland; WSA-Woody Savanna). Black lines represent linear interpolation functions (for all PFT's pooled), dotted lines 1:1 relationships.

Figure 2 - Relationships between the start day of the growing season, derived from in-situ $\left(\mathrm{SGS}_{\text {in-situ }}\right)$ VI's (see VI definitions in Table 2) and NEE (SGS NEE$_{\text {) }}$ for the different PFT's considered in this paper. Black lines represent linear interpolation functions (for all PFT's pooled), dotted lines 1:1 relationships.

Figure 3 - Relationships between the day of the start of a growing season as derived from

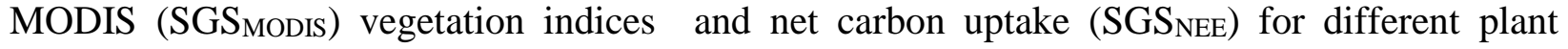
functional types as in Fig. 2, except that the start of the growing season day is derived from

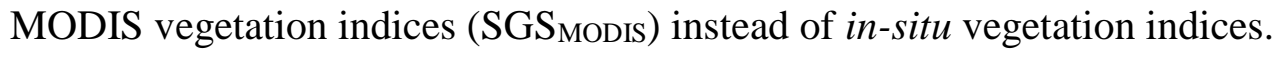

Figure 4 - Start of growing season (SGS) date estimated by using three methods. NEE is mass flux data measured at flux sites, fAPAR in-situ is fAPAR derived from in-situ radiation measurements and EVI MODIS is EVI derived from MODIS data for (a) CRO—Cropland, (b) DBF_-Deciduous Broadleaf Forest, and (c) ENF_Evergreen Needle-leaf Forest sites locate in 
the Northern Hemisphere. Dots represent mean values of SGS date estimates for the three cited variables variable and lines represent data standard errors. 